\title{
Episodic memories in anxiety disorders: clinical implications
}

\author{
Armin Zlomuzica ${ }^{1}$, Dorothea Dere $^{2}$, Alla Machulska ${ }^{1}$, Dirk Adolph $^{1}$, Ekrem Dere ${ }^{3}$ and Jürgen Margraf ${ }^{1}$ \\ ${ }^{1}$ Mental Health Research and Treatment Center, Ruhr-Universität Bochum, Bochum, Germany \\ ${ }^{2}$ Center for Psychological Consultation and Psychotherapy, Georg-August University Göttingen, Göttingen, Germany \\ ${ }^{3}$ UMR 7102, Neurobiologie des Processus Adaptatifs, Université Pierre et Marie Curie, Paris, France
}

Edited by:

Angelica Staniloiu, University of

Bielefeld, Germany

\section{Reviewed by:}

Kevin D. Beck, Rutgers New Jersey

Medical School, USA

Kristina Hennig-Fast, University of

Vienna, Austria

\section{*Correspondence:}

Armin Zlomuzica, Mental Health Research and Treatment Center,

Ruhr-Universität Bochum,

Massenbergstr. 9-13, Bochum 44787,

Germany

e-mail:armin.zlomuzica@rub.de
The aim of this review is to summarize research on the emerging role of episodic memories in the context of anxiety disorders (AD). The available literature on explicit, autobiographical, and episodic memory function in $A D$ including neuroimaging studies is critically discussed. We describe the methodological diversity of episodic memory research in AD and discuss the need for novel tests to measure episodic memory in a clinical setting. We argue that alterations in episodic memory functions might contribute to the etiology of $A D$. We further explain why future research on the interplay between episodic memory function and emotional disorders as well as its neuroanatomical foundations offers the promise to increase the effectiveness of modern psychological treatments. We conclude that one major task is to develop methods and training programs that might help patients suffering from $A D$ to better understand, interpret, and possibly actively use their episodic memories in a way that would support therapeutic interventions and counteract the occurrence of symptoms.

Keywords: episodic memory, autobiographical memory, cognitive behavioral therapy, anxiety disorders, explicit memory, post-traumatic stress disorder, panic disorder, obsessive-compulsive disorder

\section{INTRODUCTION}

\section{DIAGNOSTIC CRITERIA OF ANXIETY DISORDERS}

The diagnostic criteria for the classification of anxiety disorders (AD) have been steadily refined during the last few decades. $\mathrm{AD}$ are debilitating mental disorders that include specific phobia, generalized anxiety disorder (GAD), social phobia, and panic disorder (PD) (according to DSM-5 criteria) as well as post-traumatic stress disorder (PTSD) and obsessive-compulsive disorder (OCD) (according to the ICD-10 criteria, which include PTSD and OCD in the group of $\mathrm{AD}$ ). Some common symptoms of $\mathrm{AD}$ are excessive rumination, worrying, fear about the future, and active and passive avoidance behavior of the real or imagined fearful stimuli, situations, or events. It is very likely that operant and classical fear conditioning contribute strongly to the development, persistence, and generalization of inappropriate anxiety responses and that $\mathrm{AD}$ can be most parsimoniously explained by the principles of learning theory (Bouton et al., 2001).

\section{COGNITIVE AND LEARNING THEORIES OF ANXIETY DISORDERS}

The investigation of cognitive abilities in patients with $\mathrm{AD}$ has attracted increasing interest in the last decades. A great deal of clinical research has been directed toward a better understanding of mechanisms underlying changes in explicit and autobiographical memory in highly anxious individuals and patients with AD. These studies have been considerably influenced by cognitive theories of AD (Clark, 1999; Clark and Beck, 2010).

A central element of cognitive theories of $\mathrm{AD}$ is the proposition that the negative beliefs and covert cognitive avoidance behavior associated with $\mathrm{AD}$ are a result of the patient's misinterpretation of internal and external stimuli (e.g., the behavior of other individuals, fear associated stimuli from the environment, interoceptive physical sensations, and/or mental events) as being highly dangerous (Bouton et al., 2001; Mathews and MacLeod, 2005). Furthermore, avoidance behavior is maintained because anxiety patients tend to selectively retrieve (personally relevant) information from the past, and in particular those information, which confirm their negative interpretation of current or anticipated situations (Clark, 1999). Likewise, learning theories emphasize the importance of analyzing personally relevant autobiographical memories in anxiety patients (e.g., Öst and Hugdahl, 1981). The examination of the patient's retrospective memory can reveal the fear conditioning events that have led to the disorder and help to explain the development of negative beliefs and avoidance behavior in these individuals (Öst and Hugdahl, 1981).

\section{THE RELATION OF AUTOBIOGRAPHICAL AND EPISODIC MEMORY RETRIEVAL AND ANXIETY-RELATED SYMPTOMS}

One possible factor that potentially contributes to the maintenance of negative beliefs, maladaptive emotional responses, and avoidance behavior is the dysfunctional retrieval of past experiences from autobiographical and episodic memory (Clark, 1999; Mathews and MacLeod, 2005). It is proposed that AD patients tend to explicitly re-experience past phobic experiences when confronted with the phobic stimulus, which in turn potentiates the fear responses (Fehm and Margraf, 2002; de Quervain and Margraf, 2008). Since exposure to the phobic stimulus is the rationale of exposure-based therapies in $\mathrm{AD}$ excessive retrieval of aversive multimodal memories may be even disadvantageous in the context of such an intervention. Therefore, the modulation and interruption of this "vicious circle" is a major focus of novel approaches in the 
optimization of exposure-based treatments (Fehm and Margraf, 2002; de Quervain and Margraf, 2008).

In contrast to biased retrieval of highly emotional events and stimuli in $\mathrm{AD}$, a growing body of evidence, for instance from neuropsychological investigations, has shown that individuals with clinical levels of anxiety exhibit impaired episodic memory for neutral, emotionally irrelevant information (Airaksinen et al., 2005). These findings suggest that specific characteristics in the storage and retrieval of episodic memory in $\mathrm{AD}$ depend on the emotional valence of the processed information. The assessment of everyday's episodic memory in the course of AD pathology can provide important clues on the patient's level of cognitive functioning. Normal cognitive functioning is a prerequisite for a number of therapeutic interventions, including cognitive behavioral therapy, and could also be used as an indicator of treatment prognosis and guidance for treatment planning (Tabarés-Seisdedos et al., 2008; Mur et al., 2009).

In sum, a great deal of evidence suggests that highly anxious individuals and patients with $\mathrm{AD}$ show systematic changes in explicit and/or episodic memories. However, a closer inspection of the literature reveals several methodological and conceptual issues regarding the definition and measurement of episodic memories, which makes the interpretation of current findings difficult.

\section{REVIEW OUTLINE}

The outline of this review is as follows: first, we discuss the different methods and definitions used to operationalize episodic memory. This enables us to provide a working definition of episodic memory that captures the core elements of the concept and that can be used in clinical studies. Based on this, we will provide a brief critical review of the current state of research on the changes in episodic memories in highly anxious individuals and patients with different $\mathrm{AD}$, i.e., PD, specific phobia, social phobia, PTSD, GAD, and OCD. We will also give an update on studies investigating the neurobiological underpinnings of episodic memory functions in the context of AD. Finally, we will discuss the significance of current episodic memory research for the etiology and treatment of AD.

Our overview is based on evidence accumulated from two major lines of research: (i) studies assessing explicit and autobiographical memories for emotionally loaded and/or disorder congruent information and (ii) investigations on episodic memories for neutral information (as revealed predominantly in the context of neuropsychological investigations) in different $\mathrm{AD}$ and highly anxious individuals. Whereas a comprehensive overview of the findings is beyond the scope of this review and can be found elsewhere (McNally, 1997; Coles and Heimberg, 2002; Williams et al., 2007; Mitte, 2008), our central aim is rather to draw conclusions from the findings on the interplay between episodic memory and anxiety. We will delineate that, due to methodological and conceptual issues, current research on episodic memory in clinical settings is still inconclusive. In order to produce meaningful results, clinical research should integrate recent methodological and conceptual refinements from the field of behavioral neuroscience (e.g., Kinugawa et al., 2013; Pause et al., 2013, this research topic; Pause et al., 2010). A more systematic research of episodic memory in AD will be valuable to increase our understanding of the core pathology and mechanisms underlying successful treatment of AD.

\section{THE CONCEPT OF EPISODIC MEMORY: PAST AND PRESENT}

Before summarizing previous findings on episodic memory functions in anxiety, it is essential to dissect the definition of episodic memory and how the concept of episodic memory, coined by Endel Tulving in the early 1970s (Tulving, 1972), has gradually changed and extended during the last decades (Squire, 2004).

PubMed search using the key words "episodic memory" yielded more than 6200 hits. A careful examination of this literature revealed that there is still no common consensus on the most important core elements of episodic memory and how it should be measured. In fact, numerous working definitions of episodic memory have been proposed. Unfortunately, they are very divergent and sometimes contradictory.

In the early 70s, Tulving (1972) introduced the concept of episodic memory as a system that receives and stores multimodal information about past personal events and their spatial and temporal context. More recent definitions postulate that EM is associated with autonoetic awareness, which describes a feeling that one is remembering something that has happened to oneself, is not happening presently, and is part of one's personal history (Tulving, 2002; Hampton and Schwartz, 2004; Suddendorf and Corballis, 2007).

Humans are using past experiences (episodic memory) to anticipate future events and plan their actions in these imagined scenarios (prospective memory). Thus, an important extension of the initial definition of episodic memory was that episodic memory is not only concerned with the recollection of past experiences, but also implies one's capability to imagine or pre-experience events, which may potentially happen in the future (Harris, 1984; Atance and O'Neill, 2001). The latter is referred to as episodic future thinking or prospective memory (Brandimonte et al., 1996).

Most importantly, both subsystems co-exist within the episodic memory system. For example, we remember engaging in a certain action (e.g., meeting a friend in a bar) at a specific place and time (retrospective memory), but we are also likely able to remember to initiate the same action again at a specific time-point within a spatially well-defined location (e.g., meeting another friend in a cafe). Findings from various lesion, pharmacological, and neuroimaging studies implicate that the brain structures mediating retrospective and prospective episodic memory processes are closely linked (Addis et al., 2007). The medial prefrontal cortex and the posteromedial parietal cortex as well as the medial temporal lobes seem to represent the most critical structures for these processes (Addis et al., 2007; Szpunar et al., 2007).

\section{EXPLICIT MEMORY BIAS IN ANXIETY DISORDERS}

As outlined above, a great deal of research on amnestic functions in patients with $\mathrm{AD}$ was conducted to test the predictions made by cognitive theories of AD (Bower and Cohen, 1982; Beck et al., 1985; Mogg et al., 1987; Bradley et al., 1995). Although these theories are grounded on marginally different models, they all proposed an enhanced implicit and/or explicit retrieval (defined as implicit/explicit memory bias) of disorder-specific information as a crucial factor contributing to the maintenance of anxiety 
pathology. In other words, patients with $\mathrm{AD}$ are more likely to retrieve memories that contain disorder-relevant threatening content as compared to memories bearing disorder-irrelevant neutral or positively valenced contents. In Table 1 studies on explicit memory bias in different $\mathrm{AD}$ and their major findings are summarized according to the sample characteristics, diagnostic method, and stimulus materials used.

\section{EXPLICIT MEMORY BIAS IN PANIC DISORDER AND AGORAPHOBIA}

The first studies that aimed to test the hypothesis of an explicit memory bias were performed with patients diagnosed with PD and agoraphobia (see Bower and Cohen, 1982; Nunn et al., 1984). According to DSM-5, PD is characterized by unexpected attacks of fear and anxiety, which in some cases (although not necessarily, see Margraf and Ehlers, 1989) are accompanied by strong activation of the sympathetic nervous system. Panic attacks often become chronic and can occur without clearly identifiable causes (triggers) or on occasions where escape and/or help from other persons would be difficult to obtain (the latter being diagnosed as PD with agoraphobia). PD with and without agoraphobia are believed to be based on biological and psychological processes as well as on psychophysiological interactions (Margraf et al., 1986a; Margraf and Ehlers, 1989; McNally, 1990).

In an early investigation by Nunn et al. (1984), patients with PD and agoraphobia and normal controls were instructed to recall text passages containing both, neutral as well as panic-related material. In a subsequent test performed 5 min later, agoraphobic patients recalled more propositions from the panic-related passages as compared to normal controls. This finding was replicated in a subsequent test where agoraphobic patients and controls had to recall threatening and neutral words (Nunn et al., 1984). Again, a superior retrieval of threat-related words relative to neutral words was found in agoraphobic patients. These findings are in line with cognitive and learning theory models of $\mathrm{AD}$, which assume that agoraphobic patients show increased attention to interoceptive physical perceptions while the patient's interpretation and evaluation of these perceptions is (at least partially) guided by the retrieval of episodic memories of panic-associated, threatening events (Margraf et al., 1986a,b; Margraf and Ehlers, 1989; Zucker et al., 1989; McNally, 1997; Clark, 1999).

Later on, several studies investigated whether patients with PD and agoraphobia would show an explicit memory bias for threatening and panic-related material (see Table 1). These studies typically employed experimental tasks where anxiety patients and healthy participants were instructed to memorize verbal items that were either neutral or contained threatening and/or panic-relevant information. It was found that PD patients exhibit superior recall and recognition of anxiety words (McNally et al., 1989), panicassociated words (Cloitre and Liebowitz, 1991; Becker et al., 1994, 1999; Pauli et al., 2005), socially relevant words (Beck et al., 1992), and physical-threat-related words (Lundh et al., 1997) when compared with healthy, non anxious controls. However, there are also negative findings in the literature (e.g., Pickles and van den Broek, 1988) as well as studies that suggest that the explicit memory bias in PD is highly dependent on the verbal material used (Becker et al., 1994). Becker et al. (1994) investigated the explicit memory bias in PD patients by using learning material that consisted of pleasant, unpleasant, and PD-related words. Here, patients with $\mathrm{PD}$ and normal controls were instructed to memorize these three categories of words and to image a specific, personal scene for each word. After the patients and controls had performed a tactile distractor task, explicit memory for the study items was probed with a free-recall test. While the number of correctly remembered positive and negative words was comparable between groups, PD patients recalled more PD-related words than controls.

\section{EXPLICIT MEMORY BIAS IN POST-TRAUMATIC STRESS DISORDER, SPECIFIC PHOBIA, AND SOCIAL PHOBIA}

Similar to the results obtained in PD, findings on explicit memory bias in PTSD have been relatively consistent (see Table 1). For example, by using both free and cued recall tests war veterans who had developed PTSD showed an explicit memory bias for combat words (Zeitlin and McNally, 1991; Vrana et al., 1995). Likewise, PTSD patients, who have experienced quite different types of traumatic events, including crime victims (Paunovi et al., 2002) and Holocaust survivors (Golier et al., 2003), have shown an enhanced processing and retrieval of trauma-related words. In contrast to these findings, however, a number of studies consistently reported poorer explicit memory for disorder-irrelevant information in PTSD patients (reviewed in Isaac et al., 2006; Brewin et al., 2007). These findings suggest that explicit memory alterations in PTSD are not global, affecting both trauma-related and -unrelated material. Moreover, the changes are also not unidirectional (only improvement or impairment of memory), but rather highly selective for the type of learning material (but see also section on "Episodic Memory for Neutral Information in Anxious Individuals and Patients with Anxiety Disorders").

With respect to explicit memory bias in other phobias, studies were predominantly performed with patients suffering from social or spider phobia. For spider phobia, the results are rather mixed as some studies found an enhanced retrieval of spiderrelated material (Rusted and Dighton, 1991; Watts and Coyle, 1992) while other studies showed opposite findings (Watts and Dalgleish, 1991) or reported similar performance between spider phobic and non-phobic individuals (Thorpe and Salkovskis, 2000).

The majority of studies found no evidence for an explicit memory bias for social-threat stimuli in people with social phobia or a high level of social anxiety (e.g., Rapee et al., 1994; Cloitre et al., 1995; Lundh and Öst, 1997; Brendle and Wenzel, 2004; Rinck and Becker, 2005; Wenzel et al., 2005; see Table 1). Biased retrieval in social phobia was investigated predominantly by using verbal stimuli (Coles and Heimberg, 2002), which might represent a major reason for the low number of positive results. In fact, some researchers noted that it might be more beneficial to use facial expressions of emotions instead of words to study cognitive biases in social phobia, because facial expressions of emotions in particular are the social cues by which social phobia patients are "captured" (Foa et al., 2000; Chen et al., 2002; Pishyar et al., 2004). Foa et al. (2000) provided evidence that participants with generalized social anxiety indeed show a better overall memory for facial expressions compared to non-anxious controls, but also exhibit an enhanced recognition of negative faces compared to positive 
Table 1 | Diagnostic methods and findings from studies assessing episodic memory for emotional and/or disorder-related material in different AD.

\begin{tabular}{|c|c|c|c|c|c|}
\hline Disorder & $\begin{array}{l}\text { Sample } \\
\text { characteristics }\end{array}$ & $\begin{array}{l}\text { Diagnostic } \\
\text { method(s) }\end{array}$ & Stimulus material & Memory effect(s) & Reference \\
\hline \multirow[t]{4}{*}{$\begin{array}{l}\text { PD and } \\
\text { agora- } \\
\text { phobia }\end{array}$} & \multirow[t]{2}{*}{$\begin{array}{l}\text { PD patients and } \\
\text { agoraphobia vs. } \\
\text { controls }\end{array}$} & \multirow[t]{2}{*}{ Free recall } & $\begin{array}{l}\text { Panic-related vs. neutral } \\
\text { passages or threatening } \\
\text { vs. neutral words }\end{array}$ & $\begin{array}{l}\text { Enhanced memory for } \\
\text { panic-related passages and } \\
\text { threatening words in PD }\end{array}$ & Nunn et al. (1984) \\
\hline & & & $\begin{array}{l}\text { Anxiety-, panic-, social-, } \\
\text { physical-threat words }\end{array}$ & $\begin{array}{l}\text { Enhanced memory for all word } \\
\text { types in PD }\end{array}$ & $\begin{array}{l}\text { McNally et al. (1989), Becker } \\
\text { et al. (1994), Becker et al. } \\
\text { (1999), Cloitre and Liebowitz } \\
\text { (1991), Beck et al. (1992), } \\
\text { Lundh et al. (1997) }\end{array}$ \\
\hline & \multirow[t]{2}{*}{$\begin{array}{l}\text { PD patients vs. } \\
\text { controls }\end{array}$} & Free recall & $\begin{array}{l}\text { PD-related vs. pleasant vs. } \\
\text { unpleasant words }\end{array}$ & $\begin{array}{l}\text { Enhanced memory for } \\
\text { PD-related words in PD }\end{array}$ & Becker et al. (1994) \\
\hline & & Recognition & $\begin{array}{l}\text { Panic-relevant vs. neutral } \\
\text { words }\end{array}$ & $\begin{array}{l}\text { Enhanced discrimination and } \\
\text { faster reaction times for panic } \\
\text { words in PD }\end{array}$ & Pauli et al. (2005) \\
\hline \multirow[t]{3}{*}{ PTSD } & $\begin{array}{l}\text { Crime victims with } \\
\text { acute PTSD vs. } \\
\text { controls }\end{array}$ & Free recall & $\begin{array}{l}\text { Trauma-related vs. positive } \\
\text { and neutral words }\end{array}$ & $\begin{array}{l}\text { Enhanced memory for } \\
\text { trauma-related words in PTSD }\end{array}$ & Paunovi et al. (2002) \\
\hline & $\begin{array}{l}\text { Holocaust survivors } \\
\text { with vs. without } \\
\text { PTSD vs. controls }\end{array}$ & $\begin{array}{l}\text { Paired } \\
\text { associate } \\
\text { recall }\end{array}$ & $\begin{array}{l}\text { Holocaust-related vs. } \\
\text { neutral words }\end{array}$ & $\begin{array}{l}\text { (a) Enhanced recall of } \\
\text { Holocaust-related words in PTSD } \\
\text { (b) Poorer paired associate recall } \\
\text { in PTSD }\end{array}$ & Golier et al. (2003) \\
\hline & $\begin{array}{l}\text { War veterans with } \\
\text { vs. without PTSD }\end{array}$ & $\begin{array}{l}\text { Free recall; } \\
\text { recognition }\end{array}$ & $\begin{array}{l}\text { Combat words (specific or } \\
\text { general), other } \\
\text { trauma-related vs. neutral } \\
\text { words }\end{array}$ & $\begin{array}{l}\text { Enhanced memory for emotional } \\
\text { words in PTSD }\end{array}$ & Vrana et al. (1995) \\
\hline $\begin{array}{l}\text { Specific } \\
\text { phobia }\end{array}$ & $\begin{array}{l}\text { Spider phobics vs. } \\
\text { other specific phobia } \\
\text { vs. controls }\end{array}$ & $\begin{array}{l}\text { Free recall; } \\
\text { recognition }\end{array}$ & Video clips of spiders & $\begin{array}{l}\text { No group difference on recall or } \\
\text { recognition }\end{array}$ & Thorpe and Salkovskis (2000) \\
\hline \multirow[t]{4}{*}{$\begin{array}{l}\text { Social } \\
\text { Phobia } \\
\text { (SP) }\end{array}$} & \multirow[t]{4}{*}{$\begin{array}{l}\text { High social anxiety } \\
\text { vs. low social anxiety }\end{array}$} & $\begin{array}{l}\text { Face } \\
\text { recognition }\end{array}$ & Happy vs. angry faces & $\begin{array}{l}\text { (a) No effect on recognition in } \\
\text { high social anxiety } \\
\text { (b) Enhanced recognition for } \\
\text { happy faces in low social anxiety }\end{array}$ & D'Argembeau et al. (2003) \\
\hline & & Recall & $\begin{array}{l}\text { Positive social vs. negative } \\
\text { social vs. neutral passages }\end{array}$ & $\begin{array}{l}\text { No group effect of stimulus } \\
\text { material on recall }\end{array}$ & Brendle and Wenzel (2004) \\
\hline & & & $\begin{array}{l}\text { Positive, negative vs. } \\
\text { neutral video vignettes }\end{array}$ & & Wenzel et al. (2005) \\
\hline & & Cued recall & $\begin{array}{l}\text { Positive vs. neutral vs. } \\
\text { social-threat vs. } \\
\text { physical-threat words }\end{array}$ & & Lundh and Öst (1997) \\
\hline
\end{tabular}


Table 1 | Continued

\begin{tabular}{|c|c|c|c|c|c|}
\hline Disorder & $\begin{array}{l}\text { Sample } \\
\text { characteristics }\end{array}$ & $\begin{array}{l}\text { Diagnostic } \\
\operatorname{method}(s)\end{array}$ & Stimulus material & Memory effect(s) & Reference \\
\hline & $\begin{array}{l}\text { Social phobics vs. } \\
\text { controls }\end{array}$ & $\begin{array}{l}\text { Face } \\
\text { recognition }\end{array}$ & Critical vs. accepting faces & $\begin{array}{l}\text { (a) Overall enhanced memory for } \\
\text { faces in social phobia } \\
\text { (b) Enhanced memory for critical } \\
\text { faces in social phobia } \\
\text { (c) Overall impaired memory for } \\
\text { faces in social phobia }\end{array}$ & $\begin{array}{l}\text { Lundh and Öst (1996), Foa } \\
\text { et al. (2000), Coles and } \\
\text { Heimberg (2005) } \\
\text { Pérez-López and Woody } \\
\text { (2001) }\end{array}$ \\
\hline & $\begin{array}{l}\text { Social phobia } \\
\text { patients, high social } \\
\text { anxiety vs. controls }\end{array}$ & Free recall & $\begin{array}{l}\text { Social phobic vs. neutral } \\
\text { verbal stimuli }\end{array}$ & $\begin{array}{l}\text { Enhanced recall for affectively } \\
\text { valenced words (positive and } \\
\text { threat) in all groups }\end{array}$ & $\begin{array}{l}\text { Cloitre et al. (1995), Lundh } \\
\text { and Öst (1997), Rapee et al. } \\
\text { (1994), Rinck and Becker } \\
\text { (2005) }\end{array}$ \\
\hline \multirow[t]{4}{*}{ GAD } & $\begin{array}{l}\text { GAD vs. SP vs. } \\
\text { controls }\end{array}$ & Free recall & $\begin{array}{l}\text { GAD-relevant vs. social } \\
\text { anxiety-relevant vs. } \\
\text { pleasant vs. neutral words }\end{array}$ & $\begin{array}{l}\text { (a) No group effect } \\
\text { (b) Better recall for positive } \\
\text { words in all groups }\end{array}$ & Becker et al. (1999) \\
\hline & $\begin{array}{l}\text { GAD vs. depressed } \\
\text { vs. controls }\end{array}$ & & $\begin{array}{l}\text { Anxiety-relevant vs. } \\
\text { depression-relevant vs. } \\
\text { positive vs. neutral words }\end{array}$ & $\begin{array}{l}\text { (a) Enhanced recall of } \\
\text { depression-relevant words in } \\
\text { depressed patients } \\
\text { (b) No effect of stimulus material } \\
\text { for GAD patients }\end{array}$ & Bradley et al. (1995) \\
\hline & GAD vs. controls & Recognition & $\begin{array}{l}\text { Threat-relevant vs. neutral } \\
\text { words }\end{array}$ & $\begin{array}{l}\text { (a) No group effect } \\
\text { (b) More recognition of } \\
\text { threat-words in both groups }\end{array}$ & $\begin{array}{l}\text { MacLeod and McLaughlin } \\
\text { (1995) }\end{array}$ \\
\hline & & Free recall & $\begin{array}{l}\text { Ideographically selected } \\
\text { threat words }\end{array}$ & $\begin{array}{l}\text { Enhanced recall of thread words } \\
\text { in GAD }\end{array}$ & Coles et al. (2007) \\
\hline \multirow[t]{6}{*}{ OCD } & $\begin{array}{l}\text { OCD patients (with } \\
\text { contamination fears) } \\
\text { vs. anxious and } \\
\text { healthy controls }\end{array}$ & Free recall & $\begin{array}{l}\text { Contaminated vs. clean } \\
\text { objects }\end{array}$ & $\begin{array}{l}\text { (a) Enhanced recall of } \\
\text { contaminated objects in OCD } \\
\text { (b) No group effect on recall of } \\
\text { which tissue has touched the } \\
\text { objects }\end{array}$ & $\begin{array}{l}\text { Radomsky and Rachman } \\
\text { (1999) }\end{array}$ \\
\hline & $\begin{array}{l}\text { OCD (wash) vs. OCD } \\
\text { (checking) vs. } \\
\text { socially anxious } \\
\text { patients vs. healthy } \\
\text { controls }\end{array}$ & & & $\begin{array}{l}\text { (a) No group effect for recall of } \\
\text { contaminated objects } \\
\text { (b) Enhanced recall of which } \\
\text { tissue has touched the objects }\end{array}$ & Ceschi et al. (2003) \\
\hline & $\begin{array}{l}\text { OCD patients with } \\
\text { checking behavior } \\
\text { vs. controls }\end{array}$ & & $\begin{array}{l}\text { Threat-relevant vs. neutral } \\
\text { actions }\end{array}$ & $\begin{array}{l}\text { Enhanced recall of previously } \\
\text { experienced threat-relevant } \\
\text { actions in OCD }\end{array}$ & Constans et al. (1995) \\
\hline & $\begin{array}{l}\text { OCD patients vs. } \\
\text { controls }\end{array}$ & $\begin{array}{l}\text { Directed } \\
\text { forgetting } \\
\text { paradigm; } \\
\text { free recall; } \\
\text { recognition }\end{array}$ & $\begin{array}{l}\text { Negative vs. positive vs. } \\
\text { neutral words }\end{array}$ & $\begin{array}{l}\text { Impaired ability to forget } \\
\text { negative words in OCD }\end{array}$ & Wilhelm et al. (1996) \\
\hline & $\begin{array}{l}\text { OCD patients vs. } \\
\text { anxious and } \\
\text { non-anxious controls }\end{array}$ & $\begin{array}{l}\text { Free recall; } \\
\text { confidence } \\
\text { ratings }\end{array}$ & $\begin{array}{l}\text { Safe vs. unsafe. vs neutral } \\
\text { objects }\end{array}$ & $\begin{array}{l}\text { (a) No group effect for memory } \\
\text { accuracy } \\
\text { (b) Decreased confidence for } \\
\text { unsafe objects over trials in OCD }\end{array}$ & Tolin et al. (2001) \\
\hline & $\begin{array}{l}\text { OCD patients vs. } \\
\text { subclinical checkers } \\
\text { vs. controls }\end{array}$ & $\begin{array}{l}\text { Initial-cued } \\
\text { recall; } \\
\text { confidence } \\
\text { ratings; } \\
\text { recognition }\end{array}$ & $\begin{array}{l}\text { Threat-relevant vs. neutral } \\
\text { word pairs }\end{array}$ & $\begin{array}{l}\text { (a) Impaired recognition and } \\
\text { recall in OCD patients } \\
\text { (b) Less confidence about future } \\
\text { memory performance in OCD } \\
\text { (c) No group effect for } \\
\text { threat-relevant stimuli }\end{array}$ & Tuna et al. (2005) \\
\hline
\end{tabular}


faces (see also Lundh and Öst, 1996; Coles and Heimberg, 2005; for similar results). However, it should be noted that several subsequent studies failed to replicate the findings of Foa et al. (2000) and demonstrated no differences in the recognition and recall of threatening faces between socially anxious and non-anxious persons (e.g. D'Argembeau et al., 2003; reviewed in Staugaard, 2010). Furthermore, a poorer memory for facial expressions in socially anxious participants compared to healthy controls was also demonstrated (Pérez-López and Woody, 2001). Hence, irrespective of the methodological approach, a conclusion on possible memory biases for threatening information in social phobia is still not possible and continues to be a matter of extensive research (see Staugaard, 2010; LeMoult and Joormann, 2012).

\section{EXPLICIT MEMORY BIAS IN GENERALIZED ANXIETY DISORDER AND OBSESSIVE-COMPULSIVE DISORDER}

Given the complexity of GAD, it is not surprising that most studies failed to find an explicit memory bias toward threat-related material in GAD patients (e.g., Bradley et al., 1995; MacLeod and McLaughlin, 1995; Becker et al., 1999; reviewed in Coles and Heimberg, 2002). For instance, among other methodological factors, negative findings might be due to the difficulty of finding specific, disorder-relevant trigger stimuli, associated with the GAD patient's individual domain of worries (see Coles et al., 2007). Coles et al. (2007) used verbal material with individually selected words of personal relevance to the patient's worry domain and showed that GAD patients tend to exhibit an explicit memory bias, i.e., a superior recall of threatening words as compared to neutral words.

Compared to other $\mathrm{AD}$, little research exists on explicit memory bias in OCD. The majority of the studies so far, found a bias in explicit memory for disorder congruent word-material in OCD patients (see Table 1) although conflicting results had also been reported (e.g., Tuna et al., 2005). Radomsky and Rachman (1999) reported a better memory for contaminated than for clean stimuli in OCD patients, but not in healthy and anxious controls with comparable memory abilities. In line with these results, Constans et al. (1995) reported that OCD patients with checking rituals showed an enhanced recall of previously experienced threat-related actions as compared to non-anxious participants. In another study, neutral, positive, and negative words were presented to OCD patients with different compulsions and obsessions (Wilhelm et al., 1996). In the context of a directed forgetting paradigm, OCD patients recalled more of the negative words that they were told to forget than neutral words assigned with the forget instruction (Wilhelm et al., 1996). Tolin et al. (2001) used a somewhat different approach and presented objects classified as safe, unsafe, or neutral by the participating OCD patients. In a subsequent memory test, the OCD patients, anxious and non-anxious controls were asked to recall as many of these objects as possible and to state the level of confidence in their memories. Although no differences in the recalled number of objects between the three groups were found, the confidence for the same unsafe objects decreased across trials in the group of OCD patients. In a subsequent study using a larger group of OCD patients and more specific controls, Ceschi et al. (2003) showed that OCD patients with washing and cleaning compulsions did not remember more dirty than clean objects when instructed to recall them freely. However, OCD patients showed a memory bias when asked if an object had been touched with a clean or dirty tissue, as they more often recalled the dirty tissue touching the object. It should be noted that the interpretation of these findings is relatively difficult since OCD is also associated with relatively profound deficits in executive functions (Bannon et al., 2006).

\section{EXPLICIT MEMORY BIAS IN ANXIETY DISORDERS: SUMMARY AND INTERPRETATION}

In a recent meta-analysis of studies investigating implicit and explicit memory bias in clinically anxious patients and non-clinical samples, effect sizes across all studies point toward a better explicit memory recall of threatening material in patients with $\mathrm{AD}$ relative to non-anxious and/or low-anxious controls (Mitte, 2008). Nevertheless, as reviewed above, the evaluation of explicit memory biases in $\mathrm{AD}$ is a complex research question and several methodological differences need to be taken into account when interpreting the results. The results are mixed and/or there is little evidence available to draw a definitive conclusion. Furthermore, several factors seem to modulate or even confound the observed effects. The magnitude of the explicit memory bias in anxiety populations is highly dependent on the encoding and retrieval procedure, but also on the time interval interposed between the encoding and recall phase (see Coles and Heimberg, 2002; Mitte, 2008). Most importantly, however, most of the studies conducted so far used words or other verbal stimuli like sentences or stories to study the explicit memory bias in AD (Mitte, 2008). In this regard, it was questioned whether verbal learning leads to cognitive biases to the same extent in different AD (e.g., Wenzel and Holt, 2002; Pishyar et al., 2004). While text passages might induce a more elaborative processing than single words in some AD (Wenzel and Holt, 2002), it certainly would be worth investigating whether explicit memory bias could be reliably replicated when using real-life objects and pictorial material (e.g., information from real-life situations and/or social interactions) as learning stimuli (but see Foa et al., 2000). Although the current discrepancies between studies might be due to the specific nature and the severity of the particular AD, it is also likely that the results are highly dependent on the kind of tasks used to measure explicit memory. This question is of special importance when we consider findings of explicit memory bias in $\mathrm{AD}$ as proof of alterations in episodic memory (but see Section "The Need for Novel Episodic Memory Tests in the Clinics").

\section{OVERGENERALIZED AUTOBIOGRAPHICAL MEMORIES AND BIASED RETRIEVAL OF AUTOBIOGRAPHICAL CONTENT IN ANXIETY DISORDERS}

Autobiographical memory is another important memory domain that is conceptually related to episodic memory and has been investigated in emotional disorders. The increasing interest of clinical psychologists in autobiographical memory evolved primarily from reports of overgeneralized autobiographical memory (OGM) in patients with major depression. OGM refers to problems in recalling and reporting on temporally and spatially specific events of one's own personal past.

Up to now, autobiographical memory has been mainly assessed with the Autobiographical Memory Test (AMT), introduced by 
Williams and Broadbent (1986). In the AMT, participants are instructed to describe specific memories in response to cue words with different valences. As part of the instructions, participants are told that the remembered episode should be an outstanding event, which happened on a particular day and took place at a certain location. Reported memories are coded with regard to their specificity by an independent rater. Only when the participants provide information about the time and the particular place of the reported event, it is rated as a specific memory. In contrast, if participants report more generic personal memories based on repeated experiences or entire periods in their lives, these memories are classified as OGM. However, it is important to note that most versions of the AMT involve response-time limits of 30 or $60 \mathrm{~s}$ and that omissions are in some cases added to the OGM score (Van Vreeswijk and de Wilde, 2004; Griffith et al., 2012). Therefore, one has to consider that any physiological process or pathology involving slowing of reaction times or response latencies can confound the measurement in this task. Aged individuals or persons suffering from a depressive episode as well as patients using anxiolytic drugs are expected to have longer reaction times and response latencies.

Williams and Broadbent (1986) were the first to delineate the relation between psychopathology and OGM. In their seminal study, suicidal patients retrieved autobiographical events in a more general mode as compared to clinical and healthy controls. Later on, Williams et al. (1996) extended their initial findings and demonstrated that compared to controls, suicidal depressed patients also anticipate future events with a similar lack of episodic specificity.

\section{OVERGENERALIZED MEMORIES IN MAJOR DEPRESSION AND POST-TRAUMATIC STRESS DISORDER}

Overgeneralized autobiographical memory was proved to be a relatively stable characteristic of patients with a major depression. A higher level of OGM has been proposed to be a risk factor that increases the chance to develop major depression (Rawal and Rice, 2012), and is predictive of an unfavorable prognosis (see meta-analysis by Sumner et al., 2010).

The OGM effect is not restricted to individuals with major depression. There is also substantial evidence for OGM in patients with a PTSD (McNally et al., 1994, 1995; Moore and Zoellner, 2007; Sutherland and Bryant, 2007, 2008a; Moradi et al., 2012), cancer survivors (Kangas et al., 2005), and injured individuals with acute stress disorder (Harvey et al., 1998; see Table 2 for summary). Brown et al. (2013) recently demonstrated that PTSD patients show similar deficits in memory specificity when generating future events. However, it should be noted that to date there is no evidence for a causal relationship between OGM and the etiology of major depression and/or PTSD. Nevertheless, it has been proposed that by being overgeneral, patients with emotional disorders might try to avoid the conscious processing of highly emotional material associated with negative personal experiences (Williams et al., 2007). In particular, since the remembrance of specific aversive experiences often evokes mental images, physical symptoms, and negative emotions (Hermans et al., 2006), the retrieval of less specific/detailed memories may be a coping strategy that protects against negative affects (Hermans et al., 2006; Williams et al., 2007). This type of aversive-memory manipulation qualifies as a cognitive avoidance behavior that is associated with a negative long-term outcome: patients continue to maintain impaired affect regulation and show an increased vulnerability for future depressive and anxiety symptoms (Hermans et al., 2006; Kleim and Ehlers, 2008; Watkins, 2008).

However, it should be noted that apart from PTSD, studies conducted in patients with other AD could not demonstrate an OGM (Burke and Mathews, 1992; Wenzel et al., 2002, 2004; Wenzel and Cochran, 2006; Heidenreich et al., 2007). The presence of a fullblown major depression, as a comorbid factor, or at least some depressive-like symptoms, rather than the $\mathrm{AD}$ itself, might be the critical factor that possibly determines whether or not OGM are evident in a given disorder (Wilhelm et al., 1997; Wessel et al., 2001; Williams et al., 2007).

\section{BIASED AUTOBIOGRAPHICAL MEMORY IN ANXIETY DISORDERS}

In sum, the data reviewed so far suggest that $\mathrm{AD}$ are not directly associated with OGM. To the contrary, there is some evidence indicating that some $\mathrm{AD}$ (i.e., $\mathrm{PD}$, specific and social phobia) are characterized by a biased recall of autobiographical memories (see Table 2). In particular, it has been shown that PD patients exhibit a threat-relevant memory bias for autobiographical events. This bias is indicated by a more rapid retrieval and a more accurate reproduction of the content of threat-relevant material after being cued with PD-related thoughts (Wenzel and Cochran, 2006). Likewise, there is some evidence that socially anxious individuals show an enhanced memory of threatening and highly emotional autobiographical material (Wenzel and Cochran, 2006; Krans et al., 2013; reviewed in Morgan, 2010), which is being discussed as a core feature of the psychopathology in social anxiety (Morgan, 2010). Finally, it has been shown that spider- and blood/injury-fearful individuals exhibit an enhanced retrieval of negative autobiographical memories and show a greater specificity in the recall of episodes containing direct encounters with the feared stimuli (Wenzel et al., 2003).

\section{AUTOBIOGRAPHICAL MEMORY BIAS AND OVERGENERALIZED MEMORIES IN ANXIETY DISORDERS: SUMMARY AND DISCUSSION}

Overall, the literature on autobiographical memory function in $\mathrm{AD}$ is still inconclusive and certainly more research on this issue is needed. Some evidence is available for biases in autobiographical memory, but the results are mixed and are exclusively derived from patients with PD and specific or social phobia. Prior to a final evaluation of these studies, it is necessary to briefly discuss the pitfalls and drawbacks of the methods used in these studies. Most of the findings so far have been obtained with the AMT. While the AMT is a gold standard in research, in a recent review by Griffith et al. (2012), the authors list numerous critical issues, all of which can contribute to differences in the calculation and interpretation of AMT scores. According to this review it can be concluded (see Griffith et al., 2012 for more details) that several pitfalls listed below might have led to misleading results in the existing research literature: (I) the execution of the AMT is not standardized and differs across various studies. For example, cue words are presented orally, visually, both orally and visually, or in written form, sometimes by 
Table 2 | Findings on OGM and biased autobiographical memory in AD as assessed by different versions of the autobiographical memory test.




Table 2 | Continued

\begin{tabular}{|c|c|c|c|c|}
\hline Disorder & Sample characteristics & Material & Memory effect(s) & Reference \\
\hline $\begin{array}{l}\text { SP and } \\
\text { panic } \\
\text { disorder } \\
\text { (PD) }\end{array}$ & $\begin{array}{l}\text { SP patients vs. PD patients vs. } \\
\text { controls }\end{array}$ & $\begin{array}{l}\text { Social phobia-related vs. } \\
\text { panic-related vs. control } \\
\text { cues }\end{array}$ & $\begin{array}{l}\text { (a) Faster recall of autobiographical } \\
\text { memories after social phobia-related cues } \\
\text { in SP } \\
\text { (b) Faster recall of autobiographical } \\
\text { memories after panic-related cues in PD }\end{array}$ & $\begin{array}{l}\text { Wenzel and } \\
\text { Cochran (2006) }\end{array}$ \\
\hline $\begin{array}{l}\text { Specific } \\
\text { Phobia }\end{array}$ & $\begin{array}{l}\text { Spider fearful vs. blood/injury-fearful } \\
\text { individuals vs. controls }\end{array}$ & $\begin{array}{l}\text { Spider-related vs. } \\
\text { blood/injury-related vs. } \\
\text { neutral cue words }\end{array}$ & $\begin{array}{l}\text { Increased retrieval of generally negative } \\
\text { memories in anxious individuals }\end{array}$ & $\begin{array}{l}\text { Wenzel et al. } \\
\text { (2003) }\end{array}$ \\
\hline OCD & OCD patients vs. controls & $\begin{array}{l}\text { Positive vs. negative cue } \\
\text { words }\end{array}$ & $\begin{array}{l}\text { OGM in patients only in the presence of a } \\
\text { comorbid MD diagnosis }\end{array}$ & $\begin{array}{l}\text { Wilhelm et al. } \\
\text { (1997) }\end{array}$ \\
\hline
\end{tabular}

the researcher, sometimes within a computerized version. (II) The word lists used in the AMT were not standardized, but varied across studies in the number of items and word-type, degree of imageability, emotionality, and personal relevance of the retrieval cues. (III) Whether or not response-time limits were applied varied across studies. However, this factor has a profound impact on the way memories are encoded or retrieved. (IV) The interpretation of the AMT results was critically dependent on the study-specific scoring procedure as well as on the handling and scoring of omissions (see also Van Vreeswijk and de Wilde, 2004). Moscovitch et al. (2011) criticized the use of the AMT in the context of social phobia, since the standardized single word cues in the AMT are not sufficient to activate vivid mental images of autobiographical memories in socially anxious participants. Furthermore, the coding system of the AMT might oversimplify the complexity of remembered memories and might subsequently force raters to arbitrarily categorize a reported memory as either specific or general. Moscovitch et al. (2011) proposed that a dimensional approach would be more reasonable since the binary view on specific memories as existent or absent excludes the possibility of measuring partially accessible specific autobiographical memories.

Another important issue that should also be stressed is that a subject's performance in the AMT does not allow conclusions about whether the person accurately recollects his/her previous experiences. In its current form, the AMT does not involve a procedure that probes memory accuracy (Brewin et al., 2010). Moreover, autobiographical experiences are likely to be retrieved and narrated repeatedly, and due to their constructive and dynamic nature, there might be changes in the contents as well as the stability of a memory across time (e.g., due to reconsolidation and interference phenomena, see Schacter et al., 1998; Walker et al., 2003; Earles et al., 2008). Thus, several methodological difficulties are associated with ATM based research, and one should be cautious in drawing the definitive conclusion that autobiographical memory is not affected in a given AD.

\section{EPISODIC MEMORY FOR NEUTRAL INFORMATION IN ANXIOUS INDIVIDUALS AND PATIENTS WITH ANXIETY DISORDERS}

While the studies on explicit and autobiographical memory bias stress change in the recall of disorder congruent information in
$\mathrm{AD}$, a common secondary finding of these studies is that the recall of neutral or emotionally irrelevant material seems to be largely unaffected in AD. Can we thus conclude that global memory performance, and in particular episodic memory for neutral information, is not affected in clinically anxious people?

Studies on neurocognitive profiles in anxiety patients only partially support this assumption as outlined in the following sections.

\section{EPISODIC MEMORY FOR NEUTRAL INFORMATION IN ANXIETY DISORDERS}

An overview of studies, which assessed episodic memory for neutral information in AD is given in Table 3. While some studies reported deficits in the recall of neutral verbal information in both social phobia and PD (Lucas et al., 1991; Asmundson et al., 1994; Airaksinen et al., 2005), other studies found no evidence for such impairments in social phobia (Sachs et al., 2004; Sutterby and Bedwell, 2012) and/or PD (Gladsjo et al., 1998; Purcell et al., 1998; Boldrini et al., 2005; see Table 3).

Likewise, while extensive research on episodic memory functions has been conducted in patients with PTSD, recent reviews and meta-analysis of the existing literature on episodic, nontrauma-related memory functioning in individuals with PTSD conclude that there is no definite answer to the question (Stein et al., 2002; Neylan et al., 2004; Isaac et al., 2006), or that the association between PTSD and memory impairment appears to be only moderate (Brewin et al., 2007). A series of methodological difficulties arise when interpreting episodic memory functioning in PTSD (see Isaac et al., 2006; Brewin et al., 2007). Memory for emotionally neutral verbal information in PTSD was poorer than the recall for visual stimuli (Vasterling et al., 2002; Brewin et al., 2007). Most importantly, the difficulty of co-morbidity in the patient samples, lack of clear differentiation between PTSD patients who vary with regard to time since trauma, and deficits in attention and executive functions in PTSD (which represent core criteria for the diagnosis of PTSD according to DSM-5), could per se have contributed to the findings of impaired episodic memory in PTSD (see Isaac et al., 2006).

Several neuropsychological studies exist in OCD patients (see Greisberg and McKay, 2003 for a review of the literature). While profound deficits in episodic memory functions in OCD were 
Table 3 | Diagnostic methods and findings from studies assessing episodic memory for neutral and/or disorder-unrelated material in different $A D$ and highly-anxious individuals.

Anxiety disorder and
sample characteristics
Population-based sample comprising
individuals with PD with and without
agoraphobia, social phobia, GAD, OCD,
specific phobia vs. healthy controls

PD patients vs. controls

PD patients vs. social phobia patients vs. controls

Generalized social phobia vs. controls

PTSD patients vs. trauma-exposed individuals vs. healthy controls

OCD patients vs. PD patients vs. depressed individuals vs. controls

OCD patients vs. PD patients with agoraphobia vs. controls

OCD patients with checking behavior vs. controls

\section{Diagnostic method(s) and/or stimulus material}

Free recall of neutral words

Wechsler Memory Test (WMT); selective reminding; verbal and visual recall

Free and cued recall (California Verbal Learning Test; CVLT); visual recognition (Continuous Visual Memory Test; CVMT); Verbal and face recognition (Warrington Recognition Memory Test; WRMT)

Neuropsychological test battery (verbal learning and memory, visual memory)

Verbal and visual immediate and delayed recall of word lists and visual scenes

Different paradigms for the assessment of episodic memory for neutral information: immediate and delayed verbal recall; visual recognition memory; auditory-verbal recall (Rey Auditory-Verbal Learning Test; RAVL); visuospatial recall; CVLT; different subtests from Wechsler Memory Scale; Visual memory: Rey-Osterrieth Complex Figures Test; ROCF) etc.

Spatial short-term memory (Corsi Blocks); visual memory: recall and recognition

Spatial memory (Corsi Block Tapping Task); verbal memory (Digit Span, Buschke-Fuld Selective Reminding Test)

Digit span test; immediate and delayed recall and recognition etc.
Memory effect(s)

Reference

(a) Impaired recall in PD with and without agoraphobia, social phobia,

Airaksinen and OCD

(b) No effect in GAD and specific

phobia

(a) Impaired memory for visual, but not verbal memory in the WMT

Lucas et al. (1991)

(b) Impaired recall of verbal and visual items

(a) No group differences

(b) No effect of symptom severity on

Gladsjo et al

memory performance

(a) Reduced performance in verbal learning and memory in PD and social phobia

(b) Inhibited free recall in PD

(c) No group effect on visual memory

No group effect

Sutterby and Bedwell (2012)

Overall mixed results with respect to episodic memory for neutral (verbal and visual) information

Reviewed in Brewin et al (2007) and Isaac et al. (2006) (a) Impaired spatial recognition in OCD (b) No impairments in PD or depressed individuals

(a) Impaired verbal memory in OCD

(b) Impaired spatial memory in OCD and PD

Impaired recall and recognition in OCD
Purcell et al. (1998)

Boldrini et al (2005)

Tallis et al. (1999), Savage et al. (1999), reviewed in Greisberg and McKay (2003)

Impaired recall in OCD (depending on symptom severity and regional cerebral blood flow in the right thalamus)
Lacerda et al. (2003) 
Table 3 | Continued

\begin{tabular}{|c|c|c|c|}
\hline $\begin{array}{l}\text { Anxiety disorder and } \\
\text { sample characteristics }\end{array}$ & $\begin{array}{l}\text { Diagnostic method(s) and/or } \\
\text { stimulus material }\end{array}$ & Memory effect(s) & Reference \\
\hline OCD patients vs. controls & $\begin{array}{l}\text { Word lists; ROCF; free recall and } \\
\text { recognition of verbal and visual stimuli } \\
\text { (e.g., faces, figures) etc. }\end{array}$ & $\begin{array}{l}\text { (a) Verbal and visual episodic memory } \\
\text { impairments } \\
\text { (b) Mediation of memory performance } \\
\text { by organizational strategies } \\
\text { (c) No effect for face recognition }\end{array}$ & $\begin{array}{l}\text { Savage et al. } \\
\text { (2000), } \\
\text { Penadés et al. } \\
\text { (2005) } \\
\text { Reviewed in } \\
\text { Olley et al. } \\
\text { (2007) }\end{array}$ \\
\hline $\begin{array}{l}\text { OCD patients before vs. after treatment } \\
\text { with selective serotonin reuptake } \\
\text { inhibitors ( } 4 \text { months) }\end{array}$ & Non-verbal recall (RCFT) & $\begin{array}{l}\text { Improvement of immediate- and } \\
\text { delayed-recall after treatment }\end{array}$ & $\begin{array}{l}\text { Kang et al. } \\
\text { (2003) }\end{array}$ \\
\hline $\begin{array}{l}\text { Medicated vs. unmedicated OCD } \\
\text { patients }\end{array}$ & $\begin{array}{l}\text { Delayed verbal recall (RAVL); procedural } \\
\text { memory (computerized procedural } \\
\text { memory test) }\end{array}$ & No group effect & $\begin{array}{l}\text { Mataix-Cols } \\
\text { et al. (2002) }\end{array}$ \\
\hline $\begin{array}{l}\text { GAD patients aged }>60 \text { (before and } \\
\text { after treatment with escitalopram for } \\
12 \text { weeks) vs. controls aged }>60\end{array}$ & $\begin{array}{l}\text { Immediate and delayed recall of word } \\
\text { lists, stories, and figures }\end{array}$ & $\begin{array}{l}\text { (a) Memory impairment in GAD } \\
\text { patients before treatment } \\
\text { (b) Memory improvement in delayed } \\
\text { memory after treatment in GAD } \\
\text { patients with low cognitive scores in } \\
\text { baseline } \\
\text { (c) Strong relationship between anxiety } \\
\text { and memory improvement }\end{array}$ & $\begin{array}{l}\text { Butters et al. } \\
\text { (2011) }\end{array}$ \\
\hline
\end{tabular}

reported (Savage et al., 1999; Tallis et al., 1999; Kang et al., 2003; Kuelz et al., 2004; Boldrini et al., 2005; reviewed in Greisberg and McKay, 2003), negative findings had also been obtained (MataixCols et al., 2002; Bohne et al., 2005). As outlined above, a major factor which may account for the (episodic) memory deficits demonstrated in OCD is a concomitant impairment in executive functions due to frontal lobe dysfunction (Lacerda et al., 2003; Van den Heuvel et al., 2005; Olley et al., 2007). As a consequence, some researchers attempted to dissect the executive component from episodic memory performance in OCD. By using this approach, it was shown that an increased level of organization (in addition to the recall of information) leads to deficits in episodic memory in OCD, whereas the recall of information under controlled and well-organized conditions seems to be unaffected (Savage et al., 2000; Greisberg and McKay, 2003; Penadés et al., 2005). Thus, the memory performance of OCD patients is strongly dependent on task demands. Detrimental effects on episodic memory are more likely to occur in OCD when patients are forced to use organizational strategies during learning (Savage et al., 2000; Greisberg and McKay, 2003; Penadés et al., 2005).

Empirical evidence on episodic memory functions in GAD is relatively scarce (but see Airaksinen et al., 2005). In one of the rare comprehensive evaluations of neurocognitive functions in GAD, deficits in episodic memory (delayed visual and verbal recall) have been reported only for older adults (mean age 71.6 years) diagnosed with GAD (Butters et al., 2011). Interestingly, a 12week lasting treatment with escitalopram (Cipralex ${ }^{\circledR}$ ) improved memory in the delayed verbal memory test in GAD patients with low cognitive scores. In one of the most detailed existing studies, Airaksinen et al. (2005) assessed cognitive functions and specifically episodic memory in population-based samples of persons suffering from an $\mathrm{AD}$. In contrast to other studies, participants were recruited from a population-based sample of persons meeting the DSM-IV criteria for an AD. Overall, their results point toward significant deficits in episodic memory in all subgroups of $\mathrm{AD}$, as measured by both free and cued recall of verbal information. However, episodic memory impairments were more profound in $\mathrm{PD}$ and social phobia patients than in any other $\mathrm{AD}$ (Airaksinen et al., 2005). The impairment in episodic memory was persistent even when controlling concomitant depressive disorder, alcohol dependence/abuse, or psychopharmacological treatment as covariates. While their outcome somehow suggests that $\mathrm{AD}$ indeed have a negative influence on episodic memory functioning (Airaksinen et al., 2005), such a conclusion might be premature, as discussed in the following sections.

\section{THE NEUROANATOMY OF EPISODIC MEMORY IN ANXIETY DISORDERS}

Surprisingly, little research has been conducted to identify the neuronal mechanism, which underlies changes in episodic memory functions in the context of an AD. Most of the studies in this field have been conducted in patients diagnosed with PTSD and trauma-exposed subjects without a PTSD diagnosis. By using various imaging techniques [functional magnetic resonance imaging (fMRI) and positron emission tomography (PET)], specific neuronal activation patterns have been described in brain 
regions previously associated with episodic memory encoding and retrieval, i.e., the hippocampus, amygdala, and the prefrontal cortex. For example, Brohawn et al. (2010) assessed recognition memory for trauma-related, neutral and positive pictures in PTSD patients and trauma-exposed non-PTSD subjects by using an fMRI approach. They found increased amygdala activation during the encoding of negative (vs. neutral) pictures as well as exaggerated hippocampal activation during recognition of trauma-related pictures in PTSD diagnosed patients. Interestingly, the degree of amygdala activation was positively correlated with current PTSD symptom severity while the amount of hippocampal activation during retrieval was greater in PTSD diagnosed individuals compared to non-PTSD subjects. Dickie et al. (2008) assessed the memory for neutral and fearful face expressions in PTSD patients. They found a negative correlation between the patient's symptom severity (as assessed by Clinically Administered PTSD Scale scores) and memory performance as well as ventral medial prefrontal cortex activity elicited by the subsequently forgotten faces. Similar activation patterns during the storage and retrieval of emotionally loaded episodic memories in PTSD patients have been reported in other studies (Bremner et al., 2003a; Thomaes et al., 2009; Whalley et al., 2009; Hayes et al., 2011). There is also evidence that PTSD patients exhibit a diminished hippocampal activation during encoding (Bremner et al., 2003b), as well as an abnormal regional blood flow response (by using PET) in the hippocampus during the recollection (Shin et al., 2004) of neutral material. In a recent, quite interesting, study by Dickie et al. (2011), changes in neuronal activation during the performance in an emotional face memory encoding task have been reported in patients who recovered from PTSD symptoms. In particular, PTSD patients showing symptom improvement over several months exhibited specific changes in memory-related activations in the hippocampal regions and the subgenual anterior cingulate cortex, suggesting that learning induced neuronal activity might serve as an indicator of PTSD recovery.

To our knowledge, there are only two reports published in which $\mathrm{fMRI}$ was recorded in other $\mathrm{AD}$ patients during episodic memory performance (Maddock et al., 2003; van Tol et al., 2012). Maddock et al. (2003) demonstrated that patients with PD engage in more intense information processing and deeper encoding when confronted with threat-related stimuli. Most importantly, this increased effort in encoding of threat-related stimuli was associated with higher neuronal activation in the posterior cingulate and dorsolateral prefrontal cortices and with better memory performance for threat-related vs. unrelated stimuli. van Tol et al. (2012) assessed encoding and recognition-associated neuronal activation in $\mathrm{AD}$ patients (diagnosed with a PD, social anxiety, and/or GAD), patients with a major depression, comorbid major depression, and healthy controls during an emotional word memory paradigm. Participants were asked to memorize positive, negative, and neutral words and complete a word-recognition task after a short retention interval. Findings from this study point toward a decrease in hippocampal activation during encoding in both patients with major depression and patients diagnosed with an AD. However, specific increase in the activation in the inferior frontal gyrus during the subsequent recognition of previously learned positive material was found exclusively in patients with AD. The observed effects were largely unaffected by medication status and regional brain volume.

Although the evidence available so far is still scarce, findings from neuroimaging studies suggest the presence of a specific and symptom-related activation pattern in brain regions, which are critical for the storage and retrieval of emotionally loaded episodic memories (see Maddock, 1999).

\section{AUTOBIOGRAPHICAL VS. EPISODIC MEMORY: DIFFERENT SIDES OF THE SAME COIN?}

The episodic memory system is required for the storage of highly detailed knowledge of past experiences including spatial and temporal context as well as the internal state of the individual during the encoding of the experienced event [including a blueprint of emotions, perceptions, and thoughts in this situation (Dere et al., 2010)]. In contrast, the autobiographical memory system stores parts of the content and context information of an episodic memory and modifies and extends this content information with knowledge from the semantic memory system (reconsolidationextension phenomenon). In other words, the autobiographical memory system modifies and integrates episodic memories into the individual's biography that take the form of a semantic biographical memory. The important difference between autobiographical and episodic memories is that autobiographical memory can be de-emotionalized, modified, and extended by semantic knowledge in terms of its content (there is evidence that the content of autobiographical memories changes over time with each retrieval-extension-reconsolidation round). Furthermore, it does not necessarily contain a blueprint of the internal state of the individual during encoding and is therefore not associated with a reliving of the experience during recollection as postulated by Tulving (Tulving, 2002; Dere et al., 2010). Thus, autobiographical memories are semantic memories of biographical facts containing some of the information associated with an episodic memory, but are not associated with phenomenological aspects of remembering a past episode (autonoetic awareness), as was originally proposed by Endel Tulving (Tulving, 2002, but see Conway, 2001). Fivush (2011) argues for a developmental distinction of episodic and autobiographical memory. He describes a developmental model where autobiographical memories are built on episodic representations and bind past events together into a personal history. Within this model, autobiographical memories are supposed to act beyond the episodic memory function and represent the central component for guiding current and future behavior (Fivush, 2011). Given these theoretical distinctions between episodic and autobiographical memory, the AMT should not be applied to measure episodic memory function.

\section{AUTOBIOGRAPHICAL VS. VERBAL EPISODIC-LIKE MEMORY: SAME OR DIFFERENT?}

The AMT also differs from the assessment of episodic memory through the reproduction of learned lists of items (words, pictures, or faces) in a laboratory setting (Gilboa, 2004; McDermott et al., 2009; Fivush, 2011). The verbal memory test is also not a valid measure of episodic memory function, since it lacks the assessment of the recollection of spatial and temporal information and should be considered as measuring only an episodic-like memory. 
The neuroanatomy of verbal episodic-like and autobiographical memory has been reported to be only partially overlapping. There were substantial differences in the neuronal activation patterns between verbal episodic-like memories and autobiographical memories (Gilboa, 2004; Burianova and Grady, 2007; McDermott et al., 2009). Additionally, differences in the temporal dynamics related to the retrieval of autobiographical and verbal episodic-like memory allowed a further distinction between these two memory systems (Conway, 2001).

\section{THE NEED FOR NOVEL EPISODIC MEMORY TESTS IN THE CLINICS}

The majority of studies so far used verbal or in some rare cases visual learning to assess episodic memory for emotional and neutral information in AD. It is doubtful whether commonly used tests of episodic memory function are valid measures of episodic memory in a clinical setting (irrespective of whether they rely on the participants' ability to learn words and/or photographs and remember these at a later point via recall, cued recall, or recognition test). One problem raised is that such paradigms measure only one isolated core component of episodic memory, rather than subcomponents (the memory for what, where, and when) and the binding of these components into a unified integrated memory episode according to the definition of episodic memory as a multimodal memory system (see Pause et al., 2010, 2013; Plancher et al., 2010). Verbal learning tests, for example, do not explicitly measure the memory for spatial and temporal context information associated with the learning event, and often there is no spatial and temporal component implicated in the way the verbal memory is tested (Pause et al., 2013). As a consequence, various spatiotemporal memory paradigms have recently been developed, allowing the induction and measurement of the core components of an episodic memory (event, spatial, and temporal information) under experimentally well-defined conditions (Pause et al., 2010; Bellassen et al., 2012; Plancher et al., 2012; Kinugawa et al., 2013).

Other researchers yet suggest that much of what we remember in everyday life refers to visual information embedded in scenes and past actions, and thus emphasize the importance of using ecologically valid episodic memory tasks in a laboratory setting (Piolino et al., 2009; Plancher et al., 2010, 2012). Plancher et al. (2012) used a virtual-reality-based environment in a highly ecological fashion to characterize impairments in episodic memory in amnestic mild cognitive impairment (MCI) and Alzheimer's disease. By using a multimodal approach, the memory for central and perceptual details, spatiotemporal contextual elements, and binding of these elements was assessed in an environment corresponding to real-life experiences (i.e., driving a car through a "virtual" city where different scenes and actions were presented at different locations and at different time-points). The authors found specific episodic memory profiles in amnestic MCI and Alzheimer's disease. Interestingly the patients' daily memory complaints were more highly correlated with the performance in the virtual test than with their performance in the classical neuropsychological memory test.

Irish et al. (2011) investigated episodic memory capacity in amnestic patients with MCI by using a battery of experimental tasks with a high relevance to real-world situations. MCI patients displayed impairments across all domains of episodic memory and particularly in the experimental tasks associated with actions significant in everyday functioning, e.g., remembering faces and names, finding a route, and/or remembering typical daily routine sequences (e.g., getting dressed, traveling to work, the weather that day, see Irish et al., 2011). Thus, it can be argued that episodic memory tests in the laboratory setting can capture core elements of everyday episodic memory and that impairments in specifically designed paradigms in the laboratory can be reliable indicators of changes in everyday episodic memory functions in real-life situations.

As discussed in this section, definite conclusions on possible changes in episodic memory for emotional and neutral information in highly anxious individuals and patients with $\mathrm{AD}$ cannot be drawn from the existing literature. We argue that there is still a shortage of studies using valid standardized tests to induce episodic (like) memories and their retrieval (but see Pause et al., 2013) under laboratory conditions. Furthermore, the acceptance of verbal and visual memory tasks as a measure of episodic memory functions largely neglects the complexity of the everyday episodic memory since such tests lack ecological validity and thus cannot provide insights into the individual's level of functioning in real-life situations. There is certainly also the need to develop more reality-based tests that allow a naturalistic assessment of episodic memory in $\mathrm{AD}$ that is also useful to monitor changes in response to therapeutic interventions. In this regard, already available virtual reality tests of episodic memory function that have been developed for patients with MCI an Alzheimer's disease could be adapted to $\mathrm{AD}$ patients using disease-related and non-related stimuli (Plancher et al., 2012). Of course the test has to be designed in a way that allows repeated administration in order to evaluate the outcome of pharmacological or therapeutic interventions of episodic memory performance or whether fluctuations in symptom strengths are associated with changes in episodic memory performance.

\section{THE SIGNIFICANCE OF THE EPISODIC MEMORY CONCEPT IN THE CONTEXT OF AD}

Episodic memory is presumed to have an important evolutionary function, which has remained common across different species (Allen and Fortin, 2013). This unique functional feature of the episodic memory system allows organisms to retrieve spatially and temporally specific information about single, unique experiences (Squire, 2004; Allen and Fortin, 2013). Several lines of evidence show that the retrieval of such spatiotemporal specific experiences is highly relevant for both humans as well as non-human animals (Bluck and Alea, 2002; Dere et al., 2006, 2008).

\section{EPISODIC MEMORIES, PROBLEM SOLVING, AND SELF-EFFICACY}

Episodic memory is closely related to the level of functioning in daily life (Irish et al., 2011). In order to initiate adaptive behavior in the present or immediate future, humans, as well as animals, are able to retrieve information encoded during specific events and use these informations to form "memory-based" predictions (Allen and Fortin, 2013). In particular, when faced with current and anticipated problems, one's ability to retrieve specific details from 
previous personal events can provide important clues for efficient problem solving (Bluck and Alea, 2002; Williams, 2006; Beaman et al., 2007). Empirical evidence supports the link between episodic memory and problem-solving capacity, i.e., episodic simulation and/or higher specificity in autobiographic memory retrieval is associated with higher effectiveness in problem solving (Brown et al., 2012; Vandermorris et al., 2013). Accordingly, deficits in the specific retrieval of past experiences are highly correlated with poor problem solving (Evans et al., 1992; Sutherland and Bryant, 2008a; MacCallum and Bryant, 2010), which has a clinical impact and is therefore displayed in depressed (Goddard et al., 1996), suicidal (Evans et al., 1992; Pollock and Williams, 2001), and traumatized patients (Sutherland and Bryant, 2008b). However, the underlying cognitive mechanisms of the association between deficits in episodic memory functions and pathological conditions are still a matter of research (Williams, 2006; Williams et al., 2007).

There is also substantial evidence that episodic memory functions have therapeutic relevance and might be directly related to psychological treatment outcome. For instance, one of the core interventions in modern psychological therapies (i.e., cognitive behavioral therapies) for the treatment of mental diseases is to train patients to generate specific skills in order to manage current and future problems. Patients are encouraged to learn to reduce ineffective ways of reacting (e.g., showing avoidance or passivity) and instead react to problems effectively by applying new problemsolving skills (Nezu et al., 2003). The latter can be modified within the therapy context via cognitive restructuring procedures, e.g., realistic goal setting, success visualization, and use of previous negative experiences as a clue to solve present and future anticipated problems (Nezu et al., 2003). The capability to retrieve details from one's own past in a specific way as well as the ability to project oneself into the future and simulate novel events therefore has a potential influence on treatment outcome. Accordingly, instructions aimed at promoting the retrieval of specific positive memories during psychotherapy (i.e., memory specificity training) have recently been associated with greater symptom reduction in older depressed patients (Serrano et al., 2004), adolescents with depression (Neshat-Doost et al., 2013), and inpatients with depressive symptomatology (Raes et al., 2009). Likewise, psychological treatments lead to both symptom improvement and an increased retrieval of specific autobiographical memories in former depressive patients (Williams et al., 2000), patients with complicated grief (MacCallum and Bryant, 2010) as well as PTSD patients (Sutherland and Bryant, 2007). Moreover, Ehlers and Clark (2000) proposed an etiological model of PTSD in which the predictive valence of autobiographical memory capacity for the subsequent development of a PTSD plays a central role (Kleim and Ehlers, 2008). According to this model, successful integration of intrusive traumatic memories into the autobiographical memory base is considered as a critical element for a successful treatment of PTSD (Ehlers and Clark, 2000).

In a very recent study, Brown et al. (2012) suggested that therapy-induced increase in self-efficacy may have a beneficial impact on future directed episodic memory specificity and consequently problem-solving strategies. In their experimental work, they examined whether manipulating self-efficacy in healthy students has an impact on the capacity to recall the past and imagine one self in the future (mental time travel), and whether such manipulation can further influence social problem solving. They showed that compared to individuals in the low self-efficacy group, individuals in the high self-efficacy group generated past and future events with greater specificity and also performed better on social problem-solving indices. It should be noted that the majority of studies on clinical significance of episodic memory functions deal with affective disorders. Apart from PTSD (Sutherland and Bryant, 2007, 2008a), evidence for an association between therapy-induced symptom reduction, problem-solving capacity and episodic memory specificity in $\mathrm{AD}$ requires empirical confirmation.

\section{EXCESSIVE RETRIEVAL OF AVERSIVE EXPERIENCES IN THE CONTEXT OF EXPOSURE-BASED TREATMENTS}

Different lines of evidence suggest that the excessive episodic retrieval of aversive experiences may be disadvantageous and may hamper efficacy of psychotherapeutic interventions. Accordingly, the modulation of excessive retrieval (i.e., reducing excessive retrieval) of aversive episodic memories in anxiety patients might represent a mechanism to enhance the effectiveness of exposurebased treatments. Exposure-based treatments arguably represent the most effective form of a psychological intervention in the treatment of AD (Margraf, 2000). However, inter-individual differences in the treatment benefit during exposure-based therapy exist among anxiety patients. For example, a substantial proportion of anxiety patients shows only partial reduction of anxiety symptoms after exposure therapy and/or displays a high incidence of fear relapse phenomena after the completion of the treatment (Heimberg, 2002; Blanco et al., 2003; Davidson et al., 2004; Cottraux, 2005). It is proposed that exposure to a phobic stimulus not only leads to the activation of stimulus-associated fear memory, but is also connected with the retrieval of explicit fearful memories of past phobic experiences, which in turn enhances the fear responses (Lang, 1985; Foa and Kozak, 1986; Cuthbert et al., 2003). In PTSD and specific phobia, excessive retrieval of aversive memories causes re-experiencing symptoms and may reinforce negative beliefs, which may increase the avoidance behavior during exposure therapy (Rapee and Heimberg, 1997; Fehm and Margraf, 2002; de Quervain and Margraf, 2008). Interestingly, psychobiological approaches have recently been developed with the aim to reduce excessive retrieval of aversive memories in patients with $\mathrm{AD}$ in the context of an exposure-based treatment (de Quervain and Margraf, 2008). It is demonstrated that glucocorticoid administration during exposure enhances the effectiveness of exposure-based treatments in PTSD and specific phobia (Soravia et al., 2006; de Quervain et al., 2011). The exact mechanisms underlying the beneficial effect of glucocorticoids on exposure therapy benefit remain elusive. However, the administration of glucocorticoids during exposure therapy might modulate fear retrieval and thus interrupt the vicious cycle of spontaneous retrieving, re-experiencing, and reconsolidating of aversive memories in phobic patients leading to a reduction of maladaptive fear responses (de Quervain and Margraf, 2008; de Quervain et al., 2011). Similarly, the narrative exposure therapy (NET) represents an example of a behavioral intervention, which is aimed to selectively change and reorganize 
the retrieval of past emotional experiences. NET is a short-term therapy, which is shown to be an effective treatment for PTSD, especially in individuals traumatized by conflict and/or organized violence (Robjant and Fazel, 2010). During NET, PTSD patients are repeatedly exposed to emotional memories of traumatic events and trained to reorganize such high-emotional autobiographical memories into less-emotional coherent chronological narrative. In a typical NET session, patients are asked to narrate stressful life events in a chronological order. Interestingly, it has been shown that patients who are able to form a highly specific and consistent narrative of individual traumatic events benefit most from exposure therapy for PTSD (Foa and Kozak, 1986; Foa et al., 1995; Robjant and Fazel, 2010).

In sum, evidence so far suggests that valuable information on the characteristics of episodic memory alterations in various $\mathrm{AD}$ should be taken into consideration when designing and implementing a psychological treatment plan.

\section{CONCLUDING REMARKS}

The importance of episodic memories in the context of $\mathrm{AD}$ and other mental disorders is increasingly recognized in the last decades. We have discussed several methodological factors that warrant careful consideration in future research on episodic memory functions in clinical populations. We further provided arguments why clinical researchers should incorporate valid paradigms for the assessment of episodic memory functions in order to better understand the pathology and to optimize psychological treatment. The episodic memory system allows the storing and recollecting of emotional experiences and anticipation of potential emotional events in the future. The complexity of everyday episodic memory can thus not be captured through the use of verbal learning tests or other similar standardized memory tests currently used in the clinical setting. Both the recollection of past emotional experiences and the anticipation of future events can affect patient's behavior as well as patient's response to current therapeutic interventions. A major task for psychotherapists and other clinicians is to develop novel research methods and training programs that might help to understand, interpret, and possibly actively use patient's episodic memory to support therapeutic interventions and alleviate the severity and frequency of symptoms. Finally, more research is needed to understand the underlying neuronal basis of episodic memory alterations in $\mathrm{AD}$.

\section{ACKNOWLEDGMENTS}

We would like to thank Cathrin Felder and Helen Vollrath for critical reading and language editing of this manuscript. This work was supported by Grant No. DFG-DE 1149/6-1 to Ekrem Dere.

\section{REFERENCES}

Addis, D. R., Wong, A. T., and Schacter, D. L. (2007). Remembering the past and imagining the future: common and distinct neural substrates during event construction and elaboration. Neuropsychologia 45, 1363-1377. doi:10.1016/j. neuropsychologia.2006.10.016

Airaksinen, E., Larsson, M., and Forsell, Y. (2005). Neuropsychological functions in anxiety disorders in population-based samples: evidence of episodic memory dysfunction. J. Psychiatr. Res. 39, 207-214. doi:10.1016/j.jpsychires.2004.06.001

Allen, T. A., and Fortin, N. J. (2013). The evolution of episodic memory. Proc. Natl. Acad. Sci. U.S.A. 18, 10379-10386. doi:10.1073/pnas.1301199110
Asmundson, G. J., Stein, M. B., Larsen, D. K., and Walker, J. R. (1994). Neurocognitive function in panic disorder and social phobia patients. Anxiety 1, 201-207.

Atance, C. M., and O'Neill, D. K. (2001). Episodic future thinking. Trends Cogn. Sci. 5, 533-539. doi:10.1016/S1364-6613(00)01804-0

Bannon, S., Gonsalvez, C. J., Croft, R. J., and Boyce, P. M. (2006). Executive functions in obsessive-compulsive disorder: state or trait deficits? Aust. N. Z. J. Psychiatry 40, 1031-1038. doi:10.1111/j.1440-1614.2006.01928.x

Beaman, A., Pushkar, D., Etezadi, S., Bye, D., and Conway, M. (2007). Autobiographical memory specificity predicts social problem-solving ability in old and young adults. Q. J. Exp. Psychol. 60, 1275-1288. doi:10.1080/ 17470210600943450

Beck, A. T., Emery, G., and Greenberg, R. L. (1985). Anxiety Disorders and Phobias. New York: Basic Books.

Beck, J. G., Stanley, M. A., Averill, P. M., Baldwin, L. E., and Deagle, E. A. (1992). Attention and memory for threat in panic disorder. Behav. Res. Ther. 30, 619-629. doi:10.1016/0005-7967(92)90007-4

Becker, E., Rinck, M., and Margraf, J. (1994). Memory bias in panic disorder. J. Abnorm. Psychol. 103, 396-399. doi:10.1037/0021-843X.103.2.396

Becker, E. S., Roth, W. T., Andrich, M., and Margraf, J. (1999). Explicit memory in anxiety disorders. J. Abnorm. Psychol. 108, 153-163. doi:10.1037/0021-843X. 108.1.153

Bellassen, V., Iglói, K., de Souza, L. C., Dubois, B., and Rondi-Reig, L. (2012). Temporal order memory assessed during spatiotemporal navigation as a behavioral cognitive marker for differential Alzheimer's disease diagnosis. J. Neurosci. 32, 1942-1952. doi:10.1523/JNEUROSCI.4556-11.2012

Blanco, C., Raza, M. S., Schneier, F. R., and Liebowitz, M. R. (2003). The evidence based pharmacological treatment of social anxiety disorder. Int. J. Neuropsychopharmacol. 6, 427-442. doi:10.1017/S1461145703003791

Bluck, S., and Alea, N. (2002). "Exploring the functions of autobiographical memory," in Critical Advances in Reminiscence Work: From Theory to Application, eds J. D. Webster and B. K. Haight (New York: Springer), 61-75.

Bohne, A., Savage, C. R., Deckersbach, T., Keuthen, N. J., Jenike, M. A., TuschenCaffier, B., et al. (2005). Visuospatial abilities, memory, and executive functioning in trichotillomania and obsessive-compulsive disorder. J. Clin. Exp. Neuropsychol. 27, 385-399. doi:10.1080/13803390490520418

Boldrini, M., Del Pace, L., Placidi, G. P. A., Keilp, J., Ellis, S. P., Signori, S., et al. (2005). Selective cognitive deficits in obsessive-compulsive disorder compared to panic disorder with agoraphobia. Acta Psychiatr. Scand. 111, 150-158. doi:10.1111/j.1600-0447.2004.00247.x

Bouton, M. E., Mineka, S., and Barlow, D. H. (2001). A modern learning theory perspective on the etiology of panic disorder. Psychol. Rev. 108, 4-32. doi:10.1037/0033-295X.108.1.4

Bower, G. H., and Cohen, P. R. (1982). "Emotional influences in memory and thinking: data and theory," in Affect and Cognition, eds M. S. Clark and S. T. Fiske (Hillsdale, NJ: Erlbaum), 291-331.

Bradley, B. P., Mogg, K., and Williams, R. (1995). Implicit and explicit memory for emotion-congruent information in clinical depression and anxiety. Behav. Res. Ther. 33, 755-770. doi:10.1016/0005-7967(95)00029-W

Brandimonte, M., Einstein, G. O., and McDaniel, M. A. (eds) (1996). Prospective Memory: Theory and Applications. Mahwah, NJ: Erlbaum.

Bremner, J. D., Vythilingam, M., Vermetten, E., Southwick, S. M., McGlashan, T., Staib, L. H., et al. (2003a). Neural correlates of declarative memory for emotionally valenced words in women with posttraumatic stress disorder related to early childhood sexual abuse. Biol. Psychiatry 15, 879-889. doi:10.1016/S00063223(02)01891-7

Bremner, J. D., Vythilingam, M., Vermetten, E., Southwick, S. M., McGlashan, T., Nazeer, A., et al. (2003b). MRI and PET study of deficits in hippocampal structure and function in women with childhood sexual abuse and posttraumatic stress disorder. Am. J. Psychiatry 160, 924-932. doi:10.1176/appi.ajp.160.5.924

Brendle, J. R., and Wenzel, A. (2004). Differentiating between memory and interpretation biases in socially anxious and nonanxious individuals. Behav. Res. Ther. 42, 155-171. doi:10.1016/S0005-7967(03)00107-4

Brewin, C. R., Gregory, J. D., Lipton, M., and Burgess, N. (2010). Intrusive images in psychological disorders: characteristics, neural mechanisms, and treatment implications. Psychol. Rev. 117, 210-232. doi:10.1037/a0018113

Brewin, C. R., Kleiner, J. S., Vasterling, J. J., and Field, A. P. (2007). Memory for emotionally neutral information in posttraumatic stress disorder: a metaanalytic investigation. J. Abnorm. Psychol. 116, 448-463. doi:10.1037/0021-843X. 116.3.448 
Brohawn, K. H., Offringa, R., Pfaff, D. L., Hughes, K. C., and Shin, L. M. (2010). The neural correlates of emotional memory in posttraumatic stress disorder. Biol. Psychiatry 68, 1023-1030. doi:10.1016/j.biopsych.2010.07.018

Brown, A. D., Dorfman, M. L., Marmar, C. R., and Bryant, R. A. (2012). The impact of perceived self-efficacy on mental time travel and social problem solving. Conscious. Cogn. 21, 299-306. doi:10.1016/j.concog.2011.09.023

Brown, A. D., Root, J. C., Romano, T. A., Chang, L. J., Bryant, R. A., and Hirst, W. (2013). Overgeneralized autobiographical memory and future thinking in combat veterans with posttraumatic stress disorder. J. Behav. Ther. Exp. Psychiatry 44, 129-134. doi:10.1016/j.jbtep.2011.11.004

Burianova, H., and Grady, C. L. (2007). Common and unique neural activations in autobiographical, episodic, and semantic retrieval. J. Cogn. Neurosci. 19, 1520-1534. doi:10.1162/jocn.2007.19.9.1520

Burke, M., and Mathews, A. (1992). Autobiographical memory and clinical anxiety. Cogn. Emot. 6, 23-35. doi:10.1080/02699939208411056

Butters, M. A., Bhalla, R. K., Andreescu, C., Wetherell, J. L., Mantella, R., Begley, A. E., et al. (2011). Changes in neuropsychological functioning following treatment for late-life generalised anxiety disorder. Br. J. Psychiatry 199, 211-218. doi:10.1192/bjp.bp.110.090217

Ceschi, G., der Linden, M. V., Dunker, D., Perroud, A., and Bredart, S. (2003). Further exploration memory bias in compulsive washers. Behav. Res. Ther. 41, 737-747. doi:10.1016/S0005-7967(03)00040-8

Chen, Y. P., Ehlers, A., Clark, D. M., and Mansell, W. (2002). Patients with generalized social phobia direct their attention away from faces. Behav. Res. Ther. 40, 677-687. doi:10.1016/S0005-7967(01)00086-9

Clark, D. A., and Beck, A. T. (2010). Cognitive Therapy of Anxiety Disorders: Science and Practice. New York: Guilford.

Clark, D. M. (1999). Anxiety disorders: why they persist and how to treat them. Behav. Res. Ther. 37, 5-27. doi:10.1016/S0005-7967(99)00048-0

Cloitre, M., Cancienne, J., Heimberg, R. G., Holt, C. S., and Liebowitz, M. R. (1995) Memory bias does not generalize across anxiety disorders. Behav. Res. Ther. 33, 305-307. doi:10.1016/0005-7967(94)00051-K

Cloitre, M., and Liebowitz, M. R. (1991). Memory bias in panic disorder: an investigation of the cognitive avoidance hypothesis. Cognit. Ther. Res. 15, 371-386. doi:10.1007/BF01173032

Coles, M. E., and Heimberg, R. G. (2002). Memory biases in the anxiety disorders: current status. Clin. Psychol. Rev. 22, 587-627. doi:10.1016/S0272-7358(01) 00113-1

Coles, M. E., and Heimberg, R. G. (2005). Recognition bias for critical faces in social phobia: a replication and extension. Behav. Res. Ther. 43, 109-120. doi:10.1016/j.brat.2003.12.001

Coles, M. E., Turk, C. L., and Heimberg, R. G. (2007). Memory bias for threat in generalized anxiety disorder: the potential importance of stimulus relevance. Cogn. Behav. Ther. 36, 65-73. doi:10.1080/16506070601070459

Constans, J. I., Foa, E. B., Franklin, M. E., and Mathews, A. (1995). Memory for actual and imagined events in OC checkers. Behav. Res. Ther. 33, 665-671. doi:10.1016/0005-7967(94)00095-2

Conway, M. A. (2001). Sensory-perceptual episodic memory and its context: autobiographical memory. Philos. Trans. R. Soc. Lond. B. Biol. Sci. 356, 1375-1384. doi:10.1098/rstb.2001.0940

Cottraux, J. (2005). Recent developments in research and treatment for social phobia (social anxiety disorder). Curr. Opin. Psychiatry 18, 51-54.

Cuthbert, B. N., Lang, P. J., Strauss, C., Drobes, D., Patrick, C. J., and Bradley, M. M. (2003). The psychophysiology of anxiety disorder: fear memory imagery. Psychophysiology 40, 407-422. doi:10.1111/1469-8986.00043

D'Argembeau, A., Van der Linden, M., Etienne, A. M., and Comblain, C. (2003). Identity and expression memory for happy and angry faces in social anxiety. Acta Psychol. (Amst.) 114, 1-15. doi:10.1016/S0001-6918(03)00047-7

Davidson, J. R., Foa, E. B., Huppert, J. D., Keefe, F. J., Franklin, M. E., Compton, J. S., et al. (2004). Fluoxetine, comprehensive cognitive behavioral therapy, and placebo in generalized social phobia. Arch. Gen. Psychiatry 61, 1005-1013. doi:10.1001/archpsyc.61.10.1005

de Quervain, D. J., Bentz, D., Michael, T., Bolt, O. C., Wiederhold, B. K., Margraf, J., et al. (2011). Glucocorticoids enhance extinction-based psychotherapy. Proc. Natl. Acad. Sci. U.S.A. 108, 6621-6625. doi:10.1073/pnas.1018214108

de Quervain, D. J., and Margraf, J. (2008). Glucocorticoids for the treatment of post-traumatic stress disorder and phobias: a novel therapeutic approach. Eur. J. Pharmacol. 583, 365-371. doi:10.1016/j.ejphar.2007.11.068
Dere, E., Kart-Teke, E., Huston, J. P., and De Souza Silva, M. A. (2006). The case for episodic memory in animals. Neurosci. Biobehav. Rev. 30, 1206-1224. doi:10.1016/j.neubiorev.2006.09.005

Dere, E., Pause, B. M., and Pietrowsky, R. (2010). Emotion and episodic memory in neuropsychiatric disorders. Behav. Brain Res. 215, 162-171. doi:10.1016/j.bbr. 2010.03.017

Dere, E., Zlomuzica, A., Huston, J. P., Kart-Teke, E., and de Souza Silva, M. A. (2008). "Animal episodic memory," in Handbook of Episodic Memory Research, eds E. Dere, A. Easton, L. Nadel, and J. P. Huston (Amsterdam: Elsevier Science Publishers), 155-184.

Dickie, E. W., Brunet, A., Akerib, V., and Armony, J. L. (2008). An fMRI investigation of memory encoding in PTSD: influence of symptom severity. Neuropsychologia 46, 1522-1531. doi:10.1016/j.neuropsychologia.2008.01.007

Dickie, E. W., Brunet, A., Akerib, V., and Armony, J. L. (2011). Neural correlates of recovery from post-traumatic stress disorder: a longitudinal fMRI investigation of memory encoding. Neuropsychologia 49, 1771-1778. doi:10.1016/j. neuropsychologia.2011.02.055

Earles, J. L., Kersten, A. W., Curtayne, E. S., and Perle, J. G. (2008). That's the man who did it, or was it a woman? Actor similarity and binding errors in event memory. Psychon. Bull. Rev. 15, 1185-1189. doi:10.3758/PBR.15.6.1185

Ehlers, A., and Clark, D. M. (2000). A cognitive model of posttraumatic stress disorder. Behav. Res. Ther. 38, 319-345. doi:10.1016/S0005-7967(99)00123-0

Evans, J., Williams, J. M. G., O’Loughlin, S., and Howells, K. (1992). Autobiographical memory and problem-solving strategies of parasuicide patients. Psychol. Med. 22, 399-405. doi:10.1017/S0033291700030348

Fehm, L., and Margraf, J. (2002). Thought suppression: specificity in agoraphobia versus broad impairment in social phobia? Behav. Res. Ther. 40, 57-66. doi:10.1016/S0005-7967(01)00002-X

Fivush, R. (2011). The development of autobiographical memory. Annu. Rev. Psychol. 62, 559-582. doi:10.1146/annurev.psych.121208.131702

Foa, E. B., Gilboa-Schechtman, E., Amir, N., and Freshman, M. (2000). Memory bias in generalized social phobia: remembering negative emotional expressions. J. Anxiety Disord. 14, 501-519. doi:10.1016/S0887-6185(00)00036-0

Foa, E. B., and Kozak, M. J. (1986). Emotional processing of fear: exposure to corrective information. Psychol. Bull. 99, 20-35. doi:10.1037/0033-2909.99.1.20

Foa, E. B., Molnar, C., and Cashman, L. (1995). Change in rape narratives during exposure therapy for posttraumatic stress disorder. J. Trauma Stress 8, 675-690. doi:10.1002/jts. 2490080409

Gilboa, A. (2004). Autobiographical and episodic memory - one and the same? Evidence from prefrontal activation in neuroimaging studies. Neuropsychologia 42, 1336-1349. doi:10.1016/j.neuropsychologia.2004.02.014

Gladsjo, J. A., Rapaport, M. H., McKinney, R., Lucas, J. A., Rabin, A., Oliver, T., et al. (1998). A neuropsychological study of panic disorder: negative findings. J. Affect. Disord. 49, 123-131. doi:10.1016/S0165-0327(98)00006-8

Goddard, L., Dritschel, B., and Burton, A. (1996). Role of autobiographical memory in social problem solving and depression. J. Abnorm. Psychol. 105, 609-616. doi:10.1037/0021-843X.105.4.609

Golier, J. A., Yehuda, R., Lupien, S. J., and Harvey, P. D. (2003). Memory for traumarelated information in Holocaust survivors with PTSD. Psychiatry Res. 121, 133-143. doi:10.1016/S0925-4927(03)00120-3

Greisberg, S., and McKay, D. (2003). Neuropsychology of obsessive-compulsive disorder: a review and treatment implications. Clin. Psychol. Rev. 23, 95-117. doi:10.1016/S0272-7358(02)00232-5

Griffith, J. W., Sumner, J. A., Raes, F., Barnhofer, T., Debeer, E., and Hermans, D. (2012). Current psychometric and methodological issues in the measurement of overgeneral autobiographical memory. J. Behav. Ther. Exp. Psychiatry. 43(Suppl. 1), S21-S31. doi:10.1016/j.jbtep.2011.05.008

Hampton, R. R., and Schwartz, B. L. (2004). Episodic memory in nonhumans: what, and where, is when? Curr. Opin. Neurobiol. 14, 192-197. doi:10.1016/j.conb.2004. 03.006

Harris, J. E. (1984). "Remembering to do things: a forgotten topic," in Memory, Actions, and Absentmindedness, eds J. E. Harris and P. E. Morris (New York: Academic Press), 71-92.

Harvey, A. G., Bryant, R. A., and Dang, S. T. (1998). Autobiographical memory in acute stress disorder. J. Consult. Clin. Psychol. 66, 500-506. doi:10.1037/0022006X.66.3.500

Hayes, J. P., LaBar, K. S., McCarthy, G., Selgrade, E., Nasser, J., Dolcos, F., et al. (2011). Reduced hippocampal and amygdala activity predicts memory distortions for 
trauma reminders in combat-related PTSD. J. Psychiatr. Res. 45, 660-669. doi:10.1016/j.jpsychires.2010.10.007

Heidenreich, T., Junghanns-Royack, K., and Stangier, U. (2007). Specificity of autobiographical memory in social phobia and major depression. Br. J. Clin. Psychol. 46, 19-33. doi:10.1348/014466506X106218

Heimberg, R. G. (2002). Cognitive-behavioral therapy for social anxiety disorder: current status and future directions. Biol. Psychiatry 51, 101-108. doi:10.1016/ S0006-3223(01)01183-0

Hermans, D., Raes, F., Iberico, C., and Williams, J. M. G. (2006). Reduced autobiographical memory specificity, avoidance, and repression. Behav. Brain Sci. 29, 522-522. doi:10.1037/a0024535

Irish, M., Lawlor, B. A., Coen, R. F., and O'Mara, S. M. (2011). Everyday episodic memory in amnestic mild cognitive impairment: a preliminary investigation. BMC Neurosci. 12:80. doi:10.1186/1471-2202-12-80

Isaac, C. L., Cushway, D., and Jones, G. V. (2006). Is posttraumatic stress disorder associated with specific deficits in episodic memory? Clin. Psychol. Rev. 26 939-955. doi:10.1016/j.cpr.2005.12.004

Kang, D. H., Kwon, J. S., Kim, J. J., Youn, T., Park, H. J., Kim, M. S., et al. (2003). Brain glucose metabolic changes associated with neuropsychological improvements after 4 months of treatment in patients with obsessive-compulsive disorder. Acta Psychiatr. Scand. 107, 291-297. doi:10.1034/j.1600-0447.2003. 00070.x

Kangas, M., Henry, J. L., and Bryant, R. A. (2005). A prospective study of autobiographical memory and posttraumatic stress disorder following cancer. J. Consult. Clin. Psychol. 73, 293-299. doi:10.1037/0022-006X.73.2.293

Kinugawa, K., Schumm, S., Pollina, M., Depre, M., Jungbluth, C., Doulazmi, M., et al. (2013). Aging-related episodic memory decline: are emotions the key? Front. Behav. Neurosci. 7:2. doi:10.3389/fnbeh.2013.00002

Kleim, B., and Ehlers, A. (2008). Reduced autobiographical memory specificity predicts depression and posttraumatic stress disorder after recent trauma. J. Consult. Clin. Psychol. 76, 231-242. doi:10.1037/0022-006X.76.2.231

Krans, J., de Bree, J., and Bryant, R. A. (2013). Autobiographical memory bias in social anxiety. Memory 1-8. doi:10.1080/09658211.2013.844261

Kuelz, A. K., Hohagen, F., and Voderholzer, U. (2004). Neuropsychological performance in obsessive-compulsive disorder: a critical review. Biol. Psychol. 65 185-236. doi:10.1016/j.biopsycho.2003.07.007

Lacerda, A. L. T., Dalgalarrondo, P., Caetano, D., Haas, G. L., Camargo, E. E., and Keshavan, M. S. (2003). Neuropsychological performance and regional cerebral blood flow in obsessive-compulsive disorder. Prog. Neuropsychopharmacol. Biol. Psychiatry 27, 657-665. doi:10.1016/S0278-5846(03)00076-9

Lang, P. J. (1985). "The cognitive psychophysiology of emotion: fear and anxiety," in Anxiety and the Anxiety Disorders, eds A. H. Tuma and J. D. Maser (Hillsdale, NJ: Erlbaum), 131-170.

LeMoult, J., and Joormann, J. (2012). Attention and memory biases in social anxiety disorder: the role of comorbid depression. Cognit. Ther. Res. 36, 47-57. doi:10.1007/s10608-010-9322-2

Lucas, J. A., Telch, M. J., and Bigler, E. D. (1991). Memory functioning in panic disorder: a neuropsychological perspective. J. Anxiety Disord. 5, 1-20. doi:10.1016/0887-6185(91)90013-J

Lundh, L. G., Czyzykow, S., and Öst, L. G. (1997). Explicit and implicit memory bias in panic disorder with agoraphobia. Behav. Res. Ther. 35, 1003-1014. doi:10.1016/S0005-7967(97)00063-6

Lundh, L. G., and Öst, L. G. (1996). Recognition bias for critical faces in social phobics. Behav. Res. Ther. 34, 787-794. doi:10.1016/0005-7967(96)00035-6

Lundh, L. G., and Öst, L. G. (1997). Explicit and implicit memory bias in social phobia: the role of subdiagnostic type. Behav. Res. Ther. 35, 305-317. doi:10.1016/S0005-7967(96)00122-2

MacCallum, F., and Bryant, R. A. (2010). Impaired social problem solving in complicated grief. Br. J. Clin. Psychol. 49, 577-590. doi:10.1348/ 014466510X487040

MacLeod, C., and McLaughlin, K. (1995). Implicit and explicit memory bias in anxiety: a conceptual replication. Behav. Res. Ther. 33, 1-14. doi:10.1016/00057967(94)E0004-3

Maddock, R. J. (1999). The retrosplenial cortex and emotion: new insights from functional neuroimaging of the human brain. Trends Neurosci. 22, 310-316. doi:10.1016/S0166-2236(98)01374-5

Maddock, R. J., Buonocore, M. H., Kile, S. J., and Garrett, A. S. (2003). Brain regions showing increased activation by threat-related words in panic disorder. Neuroreport 14, 325-328. doi:10.1097/00001756-200303030-00006
Margraf, J. (2000). Lehrbuch der Verhaltenstherapie. Berlin: Springer.

Margraf, J., and Ehlers, A. (1989). "Etiological models of panic - psychophysiological and cognitive aspects," in Panic Disorder: Research and Therapy, ed. R. Baker (Chichester: Wiley), 205-231.

Margraf, J., Ehlers, A., and Roth, W. T. (1986a). Biological models of panic disorder and agoraphobia - a review. Behav. Res. Ther. 24, 553-567. doi:10.1016/00057967(86)90036-7

Margraf, J., Ehlers, A., and Roth, W. T. (1986b). Sodium lactate infusions and panic attacks: a review and critique. Psychosom. Med. 48, 23-51.

Mataix-Cols, D., Alonso, P., Pifarre, J., Menchon, J. L., and Vallejo, J. (2002). Neuropsychological performance in medicated vs. unmedicated patients with obsessive-compulsive disorder. Psychiatry Res. 109, 255-264. doi:10.1016/S01651781(02)00024-0

Mathews, A., and MacLeod, C. (2005). Cognitive vulnerability to emotional disorders. Annu. Rev. Clin. Psychol. 1, 167-195. doi:10.1146/annurev.clinpsy.1.102803. 143916

McDermott, K. B., Szpunar, K. K., and Christ, S. E. (2009). Laboratorybased and autobiographical retrieval tasks differ substantially in their neural substrates. Neuropsychologia 47, 2290-2298. doi:10.1016/j.neuropsychologia. 2008.12.025

McNally, R. J. (1990). Psychological approaches to panic disorder: a review. Psychol. Bull. 108, 403-419. doi:10.1037/0033-2909.108.3.403

McNally, R. J. (1997). Memory and anxiety disorders. Philos. Trans. R. Soc. Lond. B. Biol. Sci. 352, 1755-1759. doi:10.1098/rstb.1997.0158

McNally, R. J., Foa, E. B., and Donnell, C. D. (1989). Memory bias for anxiety information in patients with panic disorder. Cogn. Emot. 3, 27-44. doi:10.1080/ 02699938908415234

McNally, R. J., Lasko, N. B., Macklin, M. L., and Pitman, R. K. (1995). Autobiographical memory disturbance in combat-related posttraumatic stress disorder. Behav. Res. Ther. 33, 619-630. doi:10.1016/0005-7967(95)00007-K

McNally, R. J., Litz, B. T., Prassas, A., Shin, L. M., and Weathers, F. W. (1994). Emotional priming of autobiographical memory in posttraumatic stress disorder. Cogn. Emot. 8, 351-367. doi:10.1371/journal.pone. 0058150

Mitte, K. (2008). Memory bias for threatening information in anxiety and anxiety disorders: a meta-analytic review. Psychol. Bull. 134, 886-911. doi:10.1037/ a0013343

Mogg, K., Mathews, A., and Weinman, J. (1987). Memory bias in clinical anxiety. J. Abnorm. Psychol. 96, 94-98. doi:10.1037/0021-843X.96.2.94

Moore, S. A., and Zoellner, L. A. (2007). Overgeneral autobiographical memory and traumatic events: an evaluative review. Psychol. Bull. 133, 419-437. doi:10.1037/0033-2909.133.3.419

Moradi, A. R., Abdi, A., Fathi-Ashtiani, A., Dalgleish, T., and Jobson, L. (2012). Overgeneral autobiographical memory recollection in Iranian combat veterans with posttraumatic stress disorder. Behav. Res. Ther. 50, 435-441. doi:10.1016/j.brat. 2012.03.009

Morgan, J. (2010). Autobiographical memory biases in social anxiety. Clin. Psychol. Rev. 30, 288-297. doi:10.1016/j.cpr.2009.12.003

Moscovitch, D. A., Gavric, D. L., Merrifield, C., Bielak, T., and Moscovitch, M. (2011). Retrieval properties of negative vs. positive mental images and autobiographical memories in social anxiety: outcomes with a new measure. Behav. Res. Ther. 49 , 505-517. doi:10.1016/j.brat.2011.05.009

Mur, M., Portella, M. J., Martinez-Aran, A., Pifarre, J., and Vieta, E. (2009). Influence of clinical and neuropsychological variables on the psychosocial and occupational outcome of remitted bipolar patients. Psychopathology 42, 148-156. doi:10.1159/000207456

Neshat-Doost, H. T., Dalgleish, T., Yule, W., Kalantari, M., Ahmadi, S. J., Dyregov, A., et al. (2013). Enhancing autobiographical memory specificity through cognitive training: an intervention for depression translated from basic science. Clin. Psychol. Sci. 1, 84-92. doi:10.1177/2167702612454613

Neylan, T. C., Lenoci, M., Rothlind, J., Metzler, T. J., Schuff, N., Du, A., et al. (2004). Attention, learning, and memory in posttraumatic stress disorder. J. Trauma Stress 17, 41-46. doi:10.1023/B:JOTS.0000014675.75686.ee

Nezu, A. M., Nezu, C. M., and Lombardo, E. (2003). "Problem-solving therapy," in Cognitive Behavior Therapy: Applying Empirically Supported Techniques in your Practice, eds W. O'Donohue, J. E. Fisher, and S. C. Hayes (Hoboken: John Wiley \& Sons), 301-307.

Nunn, J., Stevenson, R., and Whalan, G. (1984). Selective memory effects in agoraphobic patients. Br. J. Clin. Psychol. 23, 195-201. doi:10.1111/j.2044-8260.1984. tb00646.x 
Olley, A., Malhi, G., and Sachdev, P. (2007). Memory and executive functioning in obsessive-compulsive disorder: a selective review. J. Affect. Disord. 104, 15-23. doi:10.1016/j.jad.2007.02.023

Öst, L. G., and Hugdahl, K. (1981). Acquisition of phobias and anxiety response patterns in clinical patients. Behav. Res. Ther. 19, 439-447. doi:10.1016/00057967(81)90134-0

Pauli, P., Dengler, W., and Wiedemann, G. (2005). Implicit and explicit memory processes in panic patients as reflected in behavioral and electrophysiological measures. J. Behav. Ther. Exp. Psychiatry 36, 111-127. doi:10.1016/j.jbtep.2004. 08.003

Paunovi, N., Lundh, L. G., and Öst, L. G. (2002). Attentional and memory bias for emotional information in crime victims with acute posttraumatic stress disorder (PTSD). J. Anxiety Disord. 16, 675-692. doi:10.1016/S0887-6185(02)00136-6

Pause, B. M., Jungbluth, C., Adolph, D., Pietrowsky, R., and Dere, E. (2010). Induction and measurement of episodic memories in healthy adults. J. Neurosci. Methods 189, 88-96. doi:10.1016/j.jneumeth.2010.03.016

Pause, B. M., Zlomuzica, A., Kinugawa, K., Mariani, J., Pietrowsky, R., and Dere, E. (2013). Perspectives on episodic-like and episodic memory. Front. Behav. Neurosci. 7:33. doi:10.3389/fnbeh.2013.00033

Penadés, R., Catalán, R., Andrés, S., Salamero, M., and Gastó, C. (2005). Executive function and nonverbal memory in obsessive-compulsive disorder. Psychiatry Res. 133, 81-90. doi:10.1016/j.psychres.2004.09.005

Pérez-López, J. R., and Woody, S. R. (2001). Memory for facial expressions in social phobia. Behav. Res. Ther. 39, 967-975. doi:10.1016/S0005-7967(00)00103-0

Pickles, A. J., and van den Broek, M. D. (1988). Failure to replicate evidence for phobic schemata in agoraphobic patients. Br. J. Clin. Psychol. 27, 271-272. doi:10.1111/j.2044-8260.1988.tb00788.x

Piolino, P., Desgranges, B., and Eustache, F. (2009). Episodic autobiographical memory over the course of time: cognitive, neuropsychological and neuroimaging findings. Neuropsychologia 47, 2314-2329. doi:10.1016/j.neuropsychologia.2009. 01.020

Pishyar, R., Harris, L. M., and Menzies, R. G. (2004). Attentional bias for words and faces in social anxiety. Anxiety Stress Coping 17, 23-36. doi:10.1080/ 10615800310001601458

Plancher, G., Gyselinck, V., Nicolas, S., and Piolino, P. (2010). Age effect on components of episodic memory and feature binding: a virtual reality study. Neuropsychology 24, 379-390. doi:10.1037/a0018680

Plancher, G., Tirard, A., Gyselinck, V., Nicolas, S., and Piolino, P. (2012). Using virtual reality to characterize episodic memory profiles in amnestic mild cognitive impairment and Alzheimer's disease: influence of active and passive encoding. Neuropsychologia 50, 592-602. doi:10.1016/j.neuropsychologia.2011. 12.013

Pollock, L. R., and Williams, J. M. (2001). Effective problem solving in suicide attempters depends on specific autobiographical recall. Suicide Life Threat Behav. 31, 386-396. doi:10.1521/suli.31.4.386.22041

Purcell, R., Maruff, P., Kyrios, M., and Pantelis, C. (1998). Neuropsychological deficits in obsessive-compulsive disorder. A comparison with unipolar depression, panic disorder and, normal controls. Arch. Gen. Psychiatry 55, 415-423. doi:10.1001/archpsyc.55.5.415

Radomsky, A. S., and Rachman, S. (1999). Memory bias in obsessive-compulsive disorder (OCD). Behav. Res. Ther. 37, 605-618. doi:10.1016/S0005-7967(98) 00151-X

Raes, F., Williams, J. M. G., and Hermans, D. (2009). Reducing cognitive vulnerability to depression: a preliminary investigation of Memory Specificity Training (MEST) in patients with depressive symptomatology. J. Behav. Ther. Exp. Psychiatry 40, 24-38. doi:10.1016/j.jbtep.2008.03.001

Rapee, R. M., and Heimberg, R. G. (1997). A cognitive-behavioral model of anxiety in social phobia. Behav. Res. Ther. 35, 741-756. doi:10.1016/S0005-7967(97) 00022-3

Rapee, R. M., McCallum, S. L., Melville, L. F., Ravenscroft, H., and Rodney, J. M. (1994). Memory bias in social phobia. Behav. Res. Ther. 32, 89-99. doi:10.1016/0005-7967(94)90087-6

Rawal, A., and Rice, F. (2012). Examining overgeneral autobiographical memory as a risk factor for adolescent depression. J. Am. Acad. Child Psychol. 51, 518-527. doi:10.1016/j.jaac.2012.02.025

Rinck, M., and Becker, E. S. (2005). A comparison of attentional biases and memory biases in women with social phobia and major depression. J. Abnorm. Psychol. 114, 62-74. doi:10.1037/0021-843X.114.1.62
Robjant, K., and Fazel, M. (2010). The emerging evidence for narrative exposure therapy: a review. Clin. Psychol. Rev. 30, 1030-1039. doi:10.1016/j.cpr. 2010.07.004

Rusted, J., and Dighton, K. (1991). Selective processing of threat-related material by spider phobics in a prose recall task. Cogn. Emot. 5, 123-132. doi:10.1080/ 02699939108411029

Sachs, G., Anderer, P., Margreiter, N., Semlitsch, H., Saletu, B., and Katschnig, H. (2004). P300 event-related potentials and cognitive function in social phobia. Psychiatry Res. 131, 249-261. doi:10.1016/j.pscychresns.2004.05.005

Savage, C. R., Baer, L., Keuthen, N. J., Brown, H. D., Rauch, S. L., and Jenike, M. A. (1999). Organizational strategies mediate non-verbal memory impairment in obsessive-compulsive disorder. Biol. Psychiatry 45, 905-916. doi:10.1016/S00063223(98)00278-9

Savage, C. R., Deckersbach, T., Wilhelm, S., Rauch, S. L., Baer, L., Reid, T., et al. (2000). Strategic processing and episodic memory impairment in obsessive compulsive disorder. Neuropsychology 14, 141-151. doi:10.1037/0894-4105.14.1.141

Schacter, D. L., Norman, K. A., and Koutstaal, W. (1998). The cognitive neuroscience of constructive memory. Annu. Rev. Psychol. 49, 289-318. doi:10.1146/annurev. psych.49.1.289

Serrano, J. P., Latorre, J. M., Gatz, M., and Montanes, J. (2004). Life review therapy using autobiographical retrieval practice for older adults with depressive symptomatology. Psychol. Aging 19, 270-277. doi:10.1037/0882-7974. 19.2.272

Shin, L. M., Shin, P. S., Heckers, S., Krangel, T. S., Macklin, M. L., Orr, S. P., et al. (2004). Hippocampal function in posttraumatic stress disorder. Hippocampus 14, 292-300. doi:10.1002/hipo.10183

Soravia, L. M., Heinrichs, M., Aerni, A., Maroni, C., Schelling, G., Ehlert, U., et al. (2006). Glucocorticoids reduce phobic fear in humans. Proc. Natl. Acad. Sci. U.S.A. 103, 5585-5590. doi:10.1073/pnas.0509184103

Squire, L. R. (2004). Memory systems of the brain: a brief history and current perspective. Neurobiol. Learn. Mem. 82, 171-177. doi:10.1016/j.nlm.2004.06.005

Staugaard, S. R. (2010). Threatening faces and social anxiety: a literature review. Clin. Psychol. Rev. 30, 669-690. doi:10.1016/j.cpr.2010.05.001

Stein, M. B., Kennedy, C. M., and Twamley, E. W. (2002). Neuropsychological function in female victims of intimate partner violence with and without posttraumatic stress disorder. Biol. Psychiatry 52, 1079-1088. doi:10.1016/S00063223(02)01414-2

Suddendorf, T., and Corballis, M. C. (2007). The evolution of foresight: what is mental time travel, and is it unique to humans? Behav. Brain Sci. 30, 299-313. doi:10.1017/S0140525X07001975

Sumner, J. A., Griffith, J. W., and Mineka, S. (2010). Overgeneral autobiographical memory as a predictor of the course of depression: a meta-analysis. Behav. Res. Ther. 48, 614-625. doi:10.1016/j.brat.2010.03.013

Sutherland, K., and Bryant, R. A. (2007). Autobiographical memory in posttraumatic stress disorder before and after treatment. Behav. Res. Ther. 45, 2915-2923. doi:10.1016/j.brat.2007.08.009

Sutherland, K., and Bryant, R. A. (2008a). Social problem solving and autobiographical memory in post traumatic stress disorder. Behav. Res. Ther. 46, 154-161. doi:10.1016/j.brat.2007.10.005

Sutherland, K., and Bryant, R. A. (2008b). Autobiographical memory and the selfmemory system in posttraumatic stress disorder. J. Anxiety Disord. 22, 555-560. doi:10.1016/j.janxdis.2007.03.008

Sutterby, S. R., and Bedwell, J. S. (2012). Lack of neuropsychological deficits in generalized social phobia. PLoS ONE 7:e42675. doi:10.1371/journal.pone. 0042675

Szpunar, K. K., Watson, J. M., and McDermott, K. B. (2007). Neural substrates of envisioning the future. Proc. Natl. Acad. Sci. U.S.A. 104, 642-647. doi:10.1073/pnas.0610082104

Tabarés-Seisdedos, R., Balanzá-Martínez, V., Sánchez-Moreno, J., Martinez-Aran, A., Salazar-Fraile, J., Selva-Vera, G., et al. (2008). Neurocognitive and clinical predictors of functional outcome in patients with schizophrenia and bipolar I disorder at one-year follow-up. J. Affect. Disord. 109, 286-299. doi:10.1016/j.jad. 2007.12.234

Tallis, F., Pratt, P., and Jamani, N. (1999). Obsessive compulsive disorder, checking, and non-verbal memory: a neuropsychological investigation. Behav. Res. Ther. 37, 161-166. doi:10.1016/S0005-7967(98)00075-8

Thomaes, K., Dorrepaal, E., Draijer, N. P., de Ruiter, M. B., Elzinga, B. M., van Balkom, A. J., et al. (2009). Increased activation of the left hippocampus region 
in Complex PTSD during encoding and recognition of emotional words: a pilot study. Psychiatry Res. 171, 44-53. doi:10.1016/j.pscychresns.2008.03.003

Thorpe, S. J., and Salkovskis, P. M. (2000). Recall and recognition memory for spider information. J. Anxiety Disord. 14, 359-375. doi:10.1016/S0887-6185(00) 00028-1

Tolin, D. F., Abramowitz, J. S., Brigidi, B. D., Amir, N., Street, G. P., and Foa, E. B. (2001). Memory and memory confidence in obsessive-compulsive disorder. Behav. Res. Ther. 39, 913-927. doi:10.1016/S0005-7967(00)00064-4

Tulving, E. (1972). "Episodic and semantic memory," in Organization of Memory, eds E. Tulving and W. Donaldson (New York: Academic Press), 381-403.

Tulving, E. (2002). Episodic memory: from mind to brain. Annu. Rev. Psychol. 53, 1-25. doi:10.1146/annurev.psych.53.100901.135114

Tuna, S., Tekcan, A. I., and Topçuoglu, V. (2005). Memory and metamemory in obsessive-compulsive disorder. Behav. Res. Ther. 43, 15-27. doi:10.1016/j.brat. 2003.11.001

Van den Heuvel, O. A., Veltman, D. J., Groenewegen, H. J., Cath, D. C., van Balkom, A. J., van Hartskamp, J., et al. (2005). Frontal-striatal dysfunction during planning in obsessive-compulsive disorder. Arch. Gen. Psychiatry 62, 301-309. doi:10.1001/archpsyc.62.3.301

van Tol, M. J., Demenescu, L. R., van der Wee, N. J., Kortekaas, R., Marjan, M. N., Boer, J. A., et al. (2012). Functional magnetic resonance imaging correlates of emotional word encoding and recognition in depression and anxiety disorders. Biol. Psychiatry 71, 593-602. doi:10.1016/j.biopsych.2011.11.016

Van Vreeswijk, M. F., and de Wilde, E. (2004). Autobiographical memory specificity, psychopathology, depressed mood, and the use of the autobiographical memory test: a meta analysis. Behav. Res. Ther. 42, 731-743. doi:10.1016/S0005-7967(03) 00194-3

Vandermorris, S., Sheldon, S., Winocur, G., and Moscovitch, M. (2013). Differential contributions of executive and episodic memory functions to problem solving in younger and older adults. J. Int. Neuropsychol. Soc. 18, 1-10. doi:10.1017/S1355617713000982

Vasterling, J. J., Duke, L. M., Brailey, K., Constans, J. I., Allain, A. N. Jr., and Sutker, P. B. (2002). Attention, learning, and memory performances and intellectual resources in Vietnam Veterans: PTSD and no disorder comparisons. Neuropsychology 16, 5-14. doi:10.1037/0894-4105.16.1.5

Vrana, S. R., Roodman, A., and Beckham, J. C. (1995). Selective processing of traumarelevant words in posttraumatic stress disorder. J. Anxiety Disord. 9, 515-530. doi:10.1016/0887-6185(95)00028-M

Walker, M. P., Brakefield, T., Hobson, J. A., and Stickgold, R. (2003). Dissociable stages of human memory consolidation and reconsolidation. Nature 425, 616-620. doi:10.1038/nature01930

Watkins, E. R. (2008). Constructive and unconstructive repetitive thoughts. Psychol. Bull. 134, 163-206. doi:10.1037/0033-2909.134.2.163

Watts, F. N., and Coyle, K. (1992). Recall bias for stimulus and response anxiety words in spider phobics. Anxiety Res. 4, 315-323. doi:10.1080/08917779208248799

Watts, F. N., and Dalgleish, T. (1991). Memory for phobia-related words in spider phobics. Cogn. Emot. 5, 313-329. doi:10.1080/02699939108411043

Wenzel, A., and Cochran, C. K. (2006). Autobiographical memories prompted by automatic thoughts in panic disorder and social phobia. Cogn. Behav. Ther. 35, 129-137. doi:10.1080/16506070600583130

Wenzel, A., Finstrom, N., Jordan, J., and Brendle, J. R. (2005). Memory and interpretation of visual representations of threat in socially anxious and nonanxious individuals. Behav. Res. Ther. 43, 1029-1044. doi:10.1016/j.brat.2004.07.004

Wenzel, A., and Holt, C. S. (2002). Memory bias against threat in social phobia. Br. J. Clin. Psychol. 41, 73-79. doi:10.1348/014466502163804

Wenzel, A., Jackson, L. C., Brendle, J. R., and Pinna, K. (2003). Autobiographical memories associated with feared stimuli in fearful and nonfearful individuals. Anxiety Stress Coping 16, 1-15. doi:10.1080/1061580021000009656
Wenzel, A., Jackson, L. C., and Holt, C. S. (2002). Social phobia and the recall of autobiographical memories. Depress. Anxiety 15, 186-189. doi:10.1002/ da. 10053

Wenzel, M. M., Werner, C. K., Cochran, C. S., and Holt, A. (2004). Differential pattern of autobiographical memory retrieval in social phobic and nonanxious individuals. Behav. Cogn. Psychother. 32, 1-13.

Wessel, I., Meeren, M., Peeters, F., Arntz, A., and Merckelbach, H. (2001). Correlates of autobiographical memory specificity: the role of depression, anxiety and childhood trauma. Behav. Res. Ther. 39, 409-421. doi:10.1016/S0005-7967(00) 00011-5

Whalley, M. G., Rugg, M. D., Smith, A. P., Dolan, R. J., and Brewin, C. R. (2009) Incidental retrieval of emotional contexts in post-traumatic stress disorder and depression: an fMRI study. Brain Cogn. 69, 98-107. doi:10.1016/j.bandc.2008. 05.008

Wilhelm, S., McNally, R. J., Baer, L., and Florin, I. (1996). Directed forgetting in obsessive-compulsive disorder. Behav. Res. Ther. 34, 633-641. doi:10.1016/00057967(96)00040-X

Wilhelm, S., McNally, R. J., Baer, L., and Florin, I. (1997). Autobiographical memory in obsessive-compulsive disorder. Br. J. Clin. Psychol. 36, 21-31. doi:10.1111/j.2044-8260.1997.tb01227.x

Williams, J. M. G. (2006). Capture and rumination, functional avoidance, and executive control (CaRFAX): three processes that underlie overgeneral memory. Cogn. Emot. 20, 548-568. doi:10.1016/j.cpr.2011.10.003

Williams, J. M. G., Barnhofer, T., Crane, C., Herman, D., Raes, F., Watkins, E., et al. (2007). Autobiographical memory specificity and emotional disorder. Psychol. Bull. 133, 122-148. doi:10.1037/0033-2909.133.1.122

Williams, J. M. G., and Broadbent, K. (1986). Autobiographical memory in suicide attempters. J. Abnorm. Psychol. 95, 144-149. doi:10.1037/0021-843X.95.2.144

Williams, J. M. G., Ellis, N. C., Tyers, C., Healy, H., Rose, G., and MacLeod, A. K. (1996). The specificity of autobiographical memory and imageability of the future. Mem. Cognit. 24, 116-125. doi:10.3758/BF03197278

Williams, J. M. G., Teasdale, J. D., Segal, Z. V., and Soulsby, J. (2000). Mindfulnessbased cognitive therapy reduces overgeneral autobiographical memory in formerly depressed patients. J. Abnorm. Psychol. 109, 150-155. doi:10.1037/0021843X.109.1.150

Zeitlin, S. B., and McNally, R. J. (1991). Implicit and explicit memory bias for threat in post-traumatic stress disorder. Behav. Res. Ther. 29, 451-457. doi:10.1016/0005-7967(91)90129-Q

Zucker, D., Taylor, C. B., Brouillard, M., Ehlers, A., Margraf, J., Roth, W. T., et al. (1989). Cognitive aspects of panic attacks: content, course, and relationship to laboratory stressors. Br. J. Psychiatry 155, 86-91. doi:10.1192/bjp.155.1.86

Conflict of Interest Statement: The authors declare that the research was conducted in the absence of any commercial or financial relationships that could be construed as a potential conflict of interest.

Received: 23 October 2013; accepted: 31 March 2014; published online: 24 April 2014. Citation: Zlomuzica A, Dere D, Machulska A, Adolph D, Dere E and Margraf J (2014) Episodic memories in anxiety disorders: clinical implications. Front. Behav. Neurosci. 8:131. doi: 10.3389/fnbeh.2014.00131

This article was submitted to the journal Frontiers in Behavioral Neuroscience. Copyright (c) 2014 Zlomuzica, Dere, Machulska, Adolph, Dere and Margraf. This is an open-access article distributed under the terms of the Creative Commons Attribution License (CC BY). The use, distribution or reproduction in other forums is permitted, provided the original author(s) or licensor are credited and that the original publication in this journal is cited, in accordance with accepted academic practice. No use, distribution or reproduction is permitted which does not comply with these terms. 